\title{
Assessment
}

\section{Evaluating Measurement Invariance between Parents using the Strength and Difficulties Questionnaire (SDQ)}

\begin{tabular}{|r|l|}
\hline Journal: & Assessment \\
\hline Manuscript ID: & ASMNT-14-0082.R2 \\
\hline Manuscript Type: & Original Manuscript \\
\hline Keywords: & $\begin{array}{l}\text { Measurement invariance, Exploratory Structural Equation Modeling, } \\
\text { Multitrait Multisource Model, Strengths and Difficulty Questionnaire }\end{array}$ \\
\hline \multicolumn{2}{|l}{} \\
\hline
\end{tabular}

\section{SCHOLARONE \\ Manuscripts}




\section{| SDQ MEASUREMENT INVARIANCE} 1

\begin{abstract}
Parent ratings of their children's behavioral and emotional difficulties are commonly collected via the Strength and Difficulties Questionnaire (SDQ). For the first time, this study addressed the issue of inter-parent agreement using a measurement invariance approach. Data from 695 English couples (mothers and fathers) who had rated the behavior of their $4-.25$-year 3 menthold child were used. Given the inconsistency of previous results about the SDQ factor structure, alternative measurement models were tested. A 5-factor Exploratory Structural Equation Model (ESEM) allowing for non-zero cross-loadings fitted data best. Subsequent invariance analyses revealed that the SDQ factor structure is adequately invariant across parents, with inter-rater correlations ranging from .67 to .78. Fathers reported significantly higher levels of child conduct problems, hyperactivity, and emotional symptoms, and lower levels of prosocial behavior. This suggests that mothers and fathers each provide relevant and unique information en-across a range of their child's behavioral and emotional problems.
\end{abstract}

Word count of the abstract: $148 \underline{146}$

Key words: Measurement invariance, Exploratory Structural Equation Modeling, Multitrait Multisource Model; Strengths and Difficulty Questionnaire 1
Formatted

Style Definition: Normal: Font:

Style Definition: Heading 1: Font:

Style Definition: Heading 2: Font: Italian (Italy)

Style Definition: Heading 3: Font:

Style Definition: Comment Text: Font:

Style Definition: Comment Subject: Font:

Style Definition: Balloon Text: Font:

Style Definition: Header: Font:

Style Definition: Footer: Font:

Style Definition: Default: Font:

Style Definition: Body Text Indent 2: Font:

Style Definition: Document Map: Font:

Style Definition: Caption: Font:

Style Definition: Endnote Text: Font:

Style Definition: Footnote Text: Font:

Style Definition: List Paragraph: Font:

Style Definition: Normal (Web)1: Font:

Style Definition: Plain Text: Font:

Style Definition: Normal (Web): Font:

Style Definition: Carattere Carattere7

Style Definition: Carattere Carattere6

Style Definition: Carattere Carattere5

Style Definition: Carattere Carattere4

Style Definition: Carattere Carattere3

Style Definition: Carattere Carattere9

Style Definition: Carattere Carattere10

Style Definition: Carattere Carattere8

Style Definition: Carattere Carattere2

Style Definition: Carattere Carattere1

Style Definition: Carattere Carattere

Formatted 


\section{Introduction}

The Strengths and Difficulties Questionnaire (SDQ; Goodman, 1994) is a user-friendly instrument designed for the assessment of behavioral and emotional problems in children and adolescents aged 3-16 years. Its consists of 25 items equally divided across five scales, four of which probe difficulties: emotional symptoms (EMO), conduct problems (COND), hyperactivityinattention (HYP), and peer problems (PEER); and one scale probingwhich probes strengths: prosocial behavior (PRO). The SDQ adopts a multi-informant approach, with versions designed for teachers and parents, and a self-report version for adolescents aged 11-16. Given its brief format, it is widely used as a screening tool in research, education, community, and clinical settings.

With translations into over 60 languages (Stone, Otten, Engels, Vermulst \& Janssens, 2010) there has been much evaluative research on most of the psychometric properties of the SDQ. Possibly because of the wide variety of age samples, informants and cultural differences that have featured in these studies, substantial variation can be found concerning the SDQ factor

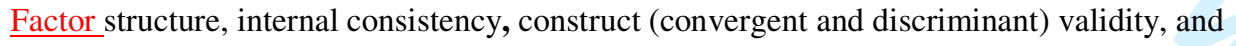
criterion (concurrent and predictive) validity. However, have been extensively tested, but very few studies have investigated the inter-parent agreement of SDQ scores relating to their child. This is somewhat surprising, as in most studies a not-otherwise-specified 'parent' provided the data, without reporting whether it was the mother or the father (let alone those cases in which only one parent is available). Thus, inter-parent agreement is a crucial issue for all contexts in 
which the SDQ is used and where both parents are informants. If it can be shown that both parents provide the same information, then either can be confidently used as a single informant. On the other hand, if systematic differences exist between parents, then the use of both parental reports would be advisable to enhance the sensitivity of scores in identifying children requiring clinical attention, as they add relevant unique variance (e.g., De Los Reyes \& Kazdin, 2005).

Past research on inter-parent agreement on reports of emotional and behavioral problems in children and adolescents has provided mixed results. While a meta analysis by Achenbach, McConaughy and Howell (1987) reported moderate, although significant, inter-parent agreement for both internalizing and externalizing problems, a similar study by Duhig, Renk, Epstein and Phares (2000) found a moderate correlation between mother and father ratings of internalizing problems, and high inter parent correlations for externalizing problems. Furthermore, inter parent agreement varied with age of the child: Achenbach et al. (1987) found a higher agreement for younger children while Duhig et al. (2000) found higher agreement for adolescents. In contrast, one consistent finding within the inter-parent agreement literature is that mothers eonsistently repert more behavioral and emetional problems than fathers, although this may alse depend on the measure employed and the age of the child (for reviews, see Davé, Nazareth, Senior \& Sherr, 2008; Mellor, Wong, \& Xu, 2011).

To the best our knowledge, only two studies have investigated the consistency and differences between mother and father ratings on the SDQ. Davé et al. (2008) collected datat from 248 dyads composed of British biological mothers and fathers who were both residing with their own 4 to-6 year-old child. Cronbach's alphas were similar for all seales (PRO: .69 vs .70 for mothers and fathers, respectively; HYP: 72 vs .74; ENO: 54 vs 59 ; COND: 59 vs .57) but PEER (.58 vs .36), where the internal consistency of the maternal scale scores was significantly 
higher than that of the paternal scale scores. Spearman's correlations among raw scores of maternal and parental scales were moderate to large (EMO: 39; COND: .51; HYP: 49; PEER:

41; PRO: 37) and fathers reported higher mean sceres than mothers when rating HYP and COND (with small to moderate effect sizes).

Mellor et al., (2011) analyzed data from the parents of 700 primary schoølchildren (mean age: 8.7 years) in southwestern China. They focused on parental differences linked to children's gender and revealed similar Cronbach's alphas on all seales (EMO: Mothers .57 and .54 for girls and boys, respectively; Fathers: .57-.56; HYP: Mothers .66-.68; Fathers: .69-.68; PEER: Mothers 32.29; Fathers: .29-25; PRO: Mothers .66-.60; Fathers: 67 .61) other than for parents ratings of boy's conduct problems (Mothers .42 .56; Fathers: 44 -40). Further analyses were carried out after the scores on COND and HYP were combined into a single externalizing problems score (EXT) though excluding PEER due to its low reliability. Pearson correlations among observed scores of mothers and fathers were in the moderate to strong range: .61 and .59 for girls and boys, respectively (.40 and .46 for EMO and .46 and .38 for PRO). Further, mother and father reports of daughters' difficulties agreed, whereas parents differed when rating the preseciat behavior of sons (mothers reported significantly higher levels of prosocial behavior).

Altheugh no consistent guidelines for interpreting inter rater reliability are reperted in the literature, if we adopt the ratings suggested by Cicchetti and Sparrow (1981; 'poor' when lower than .40 , 'fair' when ranging from .40 to .59 , 'good' when ranging from.60 to .74 and 'excellent' when higher than .74) then the coefficients reported by Davé et al. (2008) and Mellor et al. (2011) would be considered 'pøør' to 'fair'. Moreover, differences in mean scores were alse found, thus warning that the same scale score might not have the same meaning for mothers and fathers. 
In summary, the results of these two-studies suggest only moderate agreement between parents on SDQ scores, consistent not only with previous research using other childhø日d measures of behavioral and emotional problems, but also with studies on other traits such as anxiety (Moreno, Silverman, Saavedra \& Phares, 2008), Big Five personality (Tackett, 2011), and conflict and closeness in parent-child relationships (Driscoll \& Pianta, 2011). Incensistencies are thought to reflect real differences in the way that a child is experienced and/or perceived by earegivers and might stem from the tendency for mothers and fathers to play different parenting roles and to engage in different activities with a child. For example, mothers might have a higher participation in childrearing activities and spend more time with a child, particularly with infants and toddlers. Conversely, fathers might spend quality time with their children only on the weekends and play a secondary role in terms of the day to-day discipline. Moreover, achild might behave differently when alone with one of the parents, or the parents might promote different child behaviors (Davé et al., 2008; Driscoll \& Pianta, 2011; Mascendaro, Herman, \& Webster-Stratton, 2012; Mellor et al., 2011; Moreno et al., 2008; Tackett, 2011). However, it has also been shown that parental personal adjustment factors (stress, self perceptions, substance abuse and marital discord) can contribute to parental discrepancies, especially in the assessment ef externalizing problems (e.g., De Los Reyes, 2008; Liles et al., 2012).

However, one-One common and potentially problematic feature of these-studies on interparent agreement is that they usually rely on assumptions that aremight not be supported by empirical evidence. Analyses are usually carried out assuming that there is measurement invariance of the SDQmeasures between mothers and fathers, but, to. To the best of our knowledge, no study has everaddressed this issue on the SDQ. This is important because in order to compare scores across parents, it must be shown that the latent dimensions that underlie 
the SDQ measure the same construct in the same way, and that the measurements themselves operate in the same way across parents: Otherwise, mean differences and other comparisons are

likely to be invalid. Towards achieving this evience, Burns et al. (2009) proposed a means of evaluatingThe purpose of this study is thus to fill this gap in the literature.

\section{Inter-parent agreement on children's emotional and behavioral problems}

$\underline{\text { Past research on inter-parent agreement via reports of emotional and behavioral problems }}$ $\underline{\text { in children and adolescents has provided mixed results. For example, while a meta-analysis by }}$

Achenbach, McConaughy and Howell (1987) reported moderate, although significant, interparent agreement for both internalizing and externalizing problems, a similar study by Duhig,

$\underline{\text { Renk, Epstein and Phares (2000) found a moderate correlation between mother and father ratings }}$ of internalizing problems, but higher inter-parent correlations for externalizing problems.

Furthermore, inter-parent agreement varied with the age of the children: Achenbach et al. (1987) found a higher agreement for younger children while Duhig et al. (2000) found higher agreement $\underline{\text { for adolescents. In contrast, one consistent finding within the inter-parent agreement literature is }}$ that mothers consistently report more behavioral and emotional problems than do fathers, although this may also depend on the measure employed and the age of the child (for reviews, see Davé, Nazareth, Senior \& Sherr, 2008; Mellor, Wong, \& Xu, 2011). To the best our knowledge, only two studies have investigated the consistency and differences between mother and father ratings on the SDQ. Davé et al. (2008) collected data from 248 dyads composed of British biological mothers and fathers who were both residing with their own 4-to-6-year-old child. Cronbach's alphas were similar across all SDQ scales (PRO: .69 $\underline{\text { vs } .70 \text { for mothers and fathers, respectively; HYP: } .72 \text { vs .74; EMO: } .54 \text { vs 59; COND: } .59 \text { vs }}$ 
.57) but PEER (.58 vs .36), where the internal consistency of the maternal scale scores was $\underline{\text { significantly higher than that of the paternal scale scores. Spearman's correlations among raw }}$ scores of maternal and paternal scales were moderate to large (EMO: .39; COND: .51; HYP: .49; PEER: .41; PRO: .37) and fathers reported higher mean scores than mothers when rating HYP and COND (with small to moderate effect sizes).

Mellor et al. (2011) analyzed data from the parents of 700 primary school children (mean age: 8.7 years) in southwestern China. They focused on parental differences linked to children's gender and, like Davé et al. (2008), found similar Cronbach's alphas across parents and across all SDQ scales (EMO: Mothers .57 and .54 for girls and boys, respectively; Fathers: .57-.56; HYP: Mothers .66-.68; Fathers: .69-.68; PEER: Mothers .32-.29; Fathers: .29-.25; PRO: Mothers .66.60; Fathers: .67-.61) other than for paternal ratings of boy's conduct problems (Mothers .42-.56; Fathers: .44-.40). Further analyses were then carried out after the scores on COND and HYP were combined into a single externalizing problems score (EXT), and excluding PEER due to its low reliability. Pearson correlations between mother and father scores were in the moderate to strong range: .61 and .59 for girls and boys, respectively (.40 and .46 for EMO and .46 and .38 for PRO). Further, mother and father reports of the behavioral difficulties of their daughters agreed, whereas parents differed when rating the prosocial behavior of their sons (mothers reported significantly higher levels of prosocial behavior).

If we adopted the ratings suggested by Cicchetti and Sparrow (1981; 'poor' when lower than .40 , 'fair' when ranging from .40 to .59 , 'good' when ranging from. 60 to .74 and 'excellent' when higher than .74) then the inter-parent agreement coefficients reported by Davé et al. (2008) and Mellor et al. (2011) would be considered 'poor' to 'fair'. Thus, the results of these two studies $\underline{\text { suggest only moderate agreement between parents on SDQ scores and this is consistent not only }}$ 
with previous research using other childhood measures of behavioral and emotional problems, but also with studies on other traits such as anxiety (Moreno, Silverman, Saavedra \& Phares, 2008), psychopathology (De Los Reyes \& Kazdin, 2005), Big Five personality (Tackett, 2011), and conflict and closeness in parent-child relationships (Driscoll \& Pianta, 2011). These common inconsistencies are thought to reflect real differences in the way that a child is perceived by their parents and might stem from the tendency for mothers and fathers to play different parenting roles and to engage in different activities with a child. For example, mothers might have a higher participation in childrearing activities and spend more time with a child, particularly with infants and toddlers; moreover, a child might behave differently when alone with one of the parents, or $\underline{\text { the parents might promote different child behaviors (Davé et al., 2008; Driscoll \& Pianta, 2011; }}$ Mascendaro, Herman, \& Webster-Stratton, 2012; Mellor et al., 2011; Moreno et al., 2008; Tackett, 2011). However, inconsistent parent ratings seem to be more than just a result of differing parent roles. For example, it has also been shown that parental personal adjustment factors (stress, self-perceptions, substance abuse and marital discord) can contribute to parental attribution biases, especially in the assessment of their children's externalizing problems (e.g., De Los Reyes, 2008; Liles et al., 2012).

\section{Testing measurement invariance on couple data}

Mother and father scores on the SDQ can be compared as long as it can be shown that the measures provided by the questionnaire are invariant across parents, i.e., the latent dimensions that underlie the SDQ measure the same construct in the same way, and that the measurements themselves operate in the same way across parents. 
Testing the measurement invariance of parent observations of one child (i.e., withincouples) is different from testing the invariance of parents rating separate children. Instead of testing the same measurement model on two different groups as defined by parent's gender as a grouping variable, data have to be at the level of child, i.e., the unit of analysis is the child, and mothers and fathers are treated as different, but identifiable, raters of the same child. This means $\underline{\text { that, for each couple, both mother and father ratings are on the same line of data. An example of }}$ this modeling strategy has been provided by Burns et al. (2009), who evaluated measurement invariance between raters of the same child's Attention Deficit Hyperactivity Disorder (ADHD) and Oppositional Defiant Disorder (ODD). They proposed -the application of Confirmatory Factor Analysis (CFA) tewithin a: multiple indicator (SDQ items) by multitrait (SDQ constructs) by multisource (mothers and fathers) model. This analysis teststested if the measurement model for each $\underline{\mathrm{SDQ}}$ factor (representing a scale score) remainsremained invariant between mothers and fathers in all its parameters. More specifically, it tests-tested whether: (1) there are differences in the reliability of scores between parents, (2) the extent of inter-parent agreement (i.e. same factor-different source correlations), (3) -the degree of between-rater discriminant validity of the factors (i.e. if same factor-different source correlations are larger than the different factor-

different source correlations), and (4) if parents perceiveperceived equal levels of the factorseach

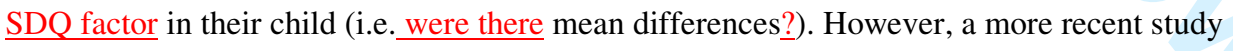
(Burns et al., 2013) questioned the use of CFA, as it requires each indicator to load on only one factor, thus assuming that secondary loadings are exactly zero (Independent Cluster Model, ICM, Church \& Burke, 1994; or perfect simple structure, Sass \& Schmitt, 2010). If one or more of the indicators have significant cross-loadings on a secondary factor, then the use of CFA might result in the failure to identify indicators with weak discriminant validity, i.e., with substantial 
loadings also on another factor or no substantial loadings on any factor. In the case of the SDQ, this would imply that a behavior that is considered an indicator of a specific problem can also be an indicator of another problem. In a CFA the more the cross-loadings depart from zero, the more the correlations among the SDQ factors will be inflated to account for non-zero crossloadings restricted to zero, thus yielding to: biased loadings, overestimated factor correlations, distorted structural relations, and lack of fit (Asparouhov \& Muthén, 2009). In response to the problems of CFA, Burns et al. (2013)

As pointed out by Booth and Hughes (2014), CFA can actually accommodate crossloadings in models. If items are hypothesized to be complex and to measure multiple aspects of the construct under study, such paths can be specified a priori. Tests of their plausibility and consistency can then be carried out within a CFA framework. However, in some cases there might be no theoretical rationale that could inform the analyst when choosing the cross-loadings to be freed. In such a situation the analyst might revert to using modification indices for exploring and specifying a well-fitting measurement model instead of following the confirmatory route (Brown, 2001). This non-confirmatory positioning of the researcher is what leads to the use of Exploratory Factor Analysis (EFA). This technique appears preferable to CFA when searching for cross-loadings, since mis-specified loadings are easier to detect through rotation of the factor matrix than through the examination of modification indices in the case of CFA. Moreover, as the process of freeing of parameters following modification indices is data-driven, the analyst is more susceptible to capitalization on chance characteristics of the data, thus undermining the generalization of results (e.g., MacCallum, Roznowski \& Necowitz, 1992).

In response to the problem of potential cross-loadings in CFA, Asparouhov and Muthén (2009) advocated the use of Exploratory Structural Equation Modeling (ESEM, Asparouhov \& 
Muthén, 2009). In these models a given number of factors can be specified grounding on a priori assumptions such that each behavior $\underline{\text { item will have as many secondary loadings as there are }}$ factors. Thus, researchers can investigate the potential for cross-loadings so as -to minimize bias. Note that ESEM is different from Exploratory Factor Analysis (EFA), as ESEM allows for an exploration of complex factor structures while allowing access to parameter estimates, standard errors, goodness-of-fit statistics, and modeling flexibility (e.g., correlating error variances, obtaining factor scores corrected for measurement error, testing measurement invariance, etc.) all features that are eommonlyotherwise associated with CFA. Although less parsimonious than CFA models with the same number of factors, an ESEM model is a principledviable alternative to a CFA model when the CFA model is unable to fit the data. Relevant to the present study, Burns et al. (2013) proposed an application of a multiple indicator by multitrait by multisource model using ESEM to test the invariance across raters (mothers, fathers and teachers) of two measures of disruptive behavior in children and adolescents. Their findings indicated that ESEM can be a more appropriate procedure in those cases in which there might be indicators with strong loadings on a secondary factor that cannot be specified a priori on sound theoretical grounds.

\section{The present study}

We organized our study as follows: First, since previous research is inconclusive about the best factor structure for the SDQ (see Section 1 of Supporting Information for a comprehensive review of the measurement models to date), we tested the model fit of a series of theoretically plausible measurement models using CFA and ESEM for mothers and fathers separately. In fact, ifThis was done to avoid the potential of testing invariance across an 
inadequately fitting measurement model. If we tested invariance with the wrong measurement model, had not carried out this first stage we could not knowhave known whether theany possible lack of fit (when it came to invariance testing) was due to an actual lack of invariance or due to a poor choice of the measurement model. Second, we tested five forms of invariance of that

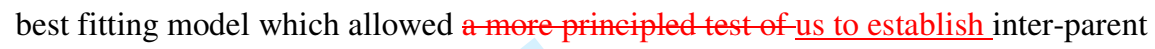
consistencies and differences on SDQ scores.

\section{Method}

Participants

Formatted

The sample for this study was UK-based and was drawn from the Families, Children and Child Care study (FCCC, www.familieschildrenchildcare.org; Sylva et al., 2007). Sampling centered on antenatal clinics and community post-natal clinics in Northern London and Oxfordshire, catering for a demographically diverse population. The recruited families came from a wide range of socio-economic backgrounds, and the attained sample was roughly comparable to the UK population at the time (see Malmberg et al., 2005).

Children in the study were followed up at 3,10, 18, 36 and 51 months. Information was collected by face-to-face interviews with mothers (all data collection waves), and questionnaires to both parents (all data collection waves). After recruitment, the sample sizes of children were $1077,1050,1036$, and 1040, at 10, 18, 36 and 51 months respectively. For the present study we used a subsample of 695 children who had both mother and father SDQ-ratings available when they were 4 years and 3 months (i.e., 51 months) old. 

1994). Each item was scored $0=$ not true, $1=$ somewhat true, and $2=$ certainly true. Complete descriptive statistics are reported in Section 2 of the Supporting Information.

\section{Analytic strategy}

Missing data procedure

The subsample had negligible item-level missingness ( $0.5 \%$ missing data-points). As we dealt with ordered categorical indicators, we used the weighted least squares treatment of missing data implemented in Mplus (Asparouhov \& Muthén, 2010), which is analogous to full information maximum likelihoød.Full Information Maximum Likelihood (FIML). This method uses all of the observed data to produce parameter estimates that maximize the probability of the observed data having come from the population implied by those estimates.

\section{SDQ Factor Structure}

Following the literature, we specified CFA models with one (Behavioral problemsProblems), three (Externalizing, Internalizing, and Prosocial Behaviors) and five (the original EMO, COND, HYP, PEER and PRO) constructs. Further, we also specified CFA models with two factors, as these would represent more parsimonious models with respect to three-factor models (i.e., Externalizing and Internalizing factors lumped together into a single Difficulties factor). In multiple factor models, latent dimensions were specified to either correlate or not. We also considered the possibility of a method factor (Dickey \& Blumberg, 2004; Palmieri \& Smith, 2007; McCrory \& Layte, 2012) that the author of the SDQ, Goodman (1994)), 
identified as a "positive construal" factor, i.e., the general extent to which each parent tends to

describing positive behaviors over and above that accounted for by trait factors (see figure in Section 3 of the Supporting Information)

In the SDQ, positive behaviors are operationalized by the items of the PRO scale but also by two items in the PEER scale (item 11 "Has at least one good friend" and item 14 "Generally liked by other children"), two items in the HYP scale (item 21 "Can stop and think things out before acting" and item 25 "Sees tasks through to the end, good attention span") and one item in the COND scale (item 7 "Generally obedient, usually does what adults request"). The specification of a method factor ean be-is a principled-way to address the issue of a residual covariance among the items that is otherwise not accounted for by the latent dimensions that they are supposed to reflect. Previous results have shown that including a method factor in analyses of the SDQ's factor structure improves model fit (McCrory \& Layte, 2012). That said, method factors can also wreck havoc in statistical models by causing problems such as non-convergence, improper solutions (i.e., parameter estimates out of range such as negative variance estimates or factor correlations greater than 1.0), and admissibility problems (due to empirical underidentification), especially when a method factor is correlated with the substantive factors (Marsh \& Grayson, 1995). This is why we examined the factor structure of the SDQ both with, and without, method factors.

As a principledan alternative to CFA, we also used 2- to 6ㄷ-factor ESEM models to test the significance of cross-loadings. As explained in the introduction, if this was the case-ESEM models would provide a better test of the discriminant validity of the items and betterallowed for

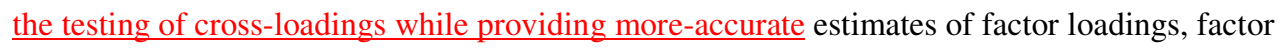


correlations and latent means. ESEM models with 2 to 5 factors eould be-(Geomin rotated) were also compared with CFA models with the same number of intercorrelated factors.

The 6 factor ESEM model was a further test of whether a less parsimonious, but potentially more informative, measurement model could provide a better fit than the 5 -factor model. Factors were Geomin rotated.

Mplus software (Muthén \& Muthén, 1998-2012) was used to test all models using the Weighted Least Squares Mean and Variance adjusted (WLSMV) estimator and Theta parameterization, which allow to taketakes into account the non-normal categorical nature of item scores (as inin Sanne, Torsheim, Heiervang, \& Stormark, 2009). In order to determine whether a common measurement model could hold for mothers and fathers, we fitted all the CFA and ESEM models separately in each group-for mothers and fathers. The goodness-of-fit of the CFA and ESEM models was assessed using Bentler's Comparative Fit Index (CFI; Bentler, 1990), the Tucker Lewis Index (TLI; Tucker \& Lewis, 1973), the Root-Mean-Square Error of Approximation (RMSEA; Steiger \& Lind, 1980), and the Weighted Root-Mean-square Residual (WRMR; Yu, 2002). Although we also report chi-square values, it must be noted that they cannot be straightforwardly evaluated when using WLSMV since degrees of freedom are

estimated "using a diagonal weight matrix with standard errors and mean- and variance adjusted chi-square test statistic that use a full weight matrix" (Muthén \& Muthén, 1998-2012, p. 603).

Following Yu (2002), we used the following cutoff values as indicative of good fit: CFI $\geq .96$, $\mathrm{TLI} \geq .95, \mathrm{RMSEA} \leq .05$, and $\mathrm{WRMR} \leq 1.00$. 
After finding a common measurement model for mothers and fathers, we then used -this model in a test of the invariance of parental ratings. Traditionally (e.g., Meredith, 1993), the sequence of invariance testing begins with a 'configural invariance' model in which all parameters are freely estimated, such that the only similarity of the overall pattern of parameters is evaluated. Technically, this model is not an invariance model in that it does not require any estimated parameters to be the same, but. Nevertheless, it is necessary since it provides beth(i) a test of the ability of the a priori model to fit the data in each group (or, in our case, child's Parental Raters) without invariance constraints and (ii) a baseline for comparing other models that impose equality constraints on the parameter estimates across groupsraters of the same child.

Configuraltests of configural invariance models are-were followed by tests of weak invariance, which constrain factor loadings to be invariant over groups.raters. If identical items have statistically equivalent loadings, then the scores of identical items show the same amount of increase between groupsraters for the same amount of increase on the latent factor (i.e., equality of scaling units). However, changes in the tatent factor-means of the latent factors can reasonably only be interpreted as changes in the latent constructs only if also the indicator means (i.e., the intercepts of respenses to individual items if the indicators are-metric, or, as it is the case of this paper, the thresholds between ordered response categories if the indicators are ordinal) are invariant across greupsraters (strong invariance). This means that at all points along the factor continuum, the same level of the factor results in statistically equivalent item average scores on identical items between greups, i.e., In other words, raters with the same level of the latent $\underline{\text { construct will have the same expected score of the measured indicators. In the case of ordinal }}$ indicators, item scores are assumed to reflect the amount of an underlying continuous and 
normally distributed variable (Muthén \& Asparouhov, 2002). The strong invariance model tests whether the thresholds (or distribution cut points, i.e., $z$-values corresponding to the cumulative probability for each response category except the highest) are equal across raters. In other words, threshold invariance is satisfied when the cut points on the underlying normal distribution are equal across raters for each indicator. If the strong invariance model shows a fit similar to the weak invariance model, it means that raters with the same level of the latent construct will have the same expected score on the measured indicators. This also implies that any observed score differences between groupsraters on identical items is not due to grouprater bias but rather due to true differences on the factorlatent construct mean. AlthoughHowever, although strong invariance allows for testing differences in latent means, it is insufficient for testing difference in manifest group(raters') means, which also require invariance of items' residual variances (or tniquenesses).to be invariant. The presence of differences in reliability (as represented in the item residual variances) across groupsraters could in fact distort mean differences on the observed scores. In the case of ordinal indicators, this means that the estimates of the residual variances of the continuous and normally distributed variables underlying item scores are constrained to be equal.

When_As mentioned earlier, when dealing with paired samples and non-normal categorical indicators, some issues must be taken into account. Testing measurement invariance on paired groups of observations as couple data is different from testing it on independent groups, since both parents report on the same child. Instead of testing the same measurement model on two different groups as defined by parent's gender as a grouping variable, we modeled the data at the child level, i.e., Since the unit of analysis was the child, and mothers and fathers

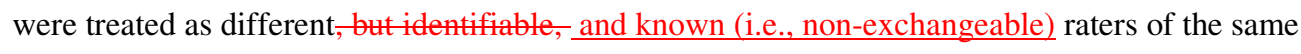


[Figure 1]

child. This means that, for each couple, both mother and father ratings were on, we specified the same line of data. This model is basically equivalent to of a single-group correlated-factor model in which the items of the scale arewere considered twice, as indicators of mother and father perceptionperceptions of their child's behavior. Each child had therefore had 50 symptom ratings, 25 rated by the mother and 25 by the father, with correlations between corresponding factors being a measure of inter-parent agreement. This also implies that the systematic residual variance (uniqueness) in each pair of identical items between parents is expected to covary because of the identical nature of the each item pair. For example, the residual variance in the item "Generally liked by other children" for mothers should covary with the item "Generally liked by other children" for fathers. Hence, we allowed correlated residual variances between like items (Figure 1).

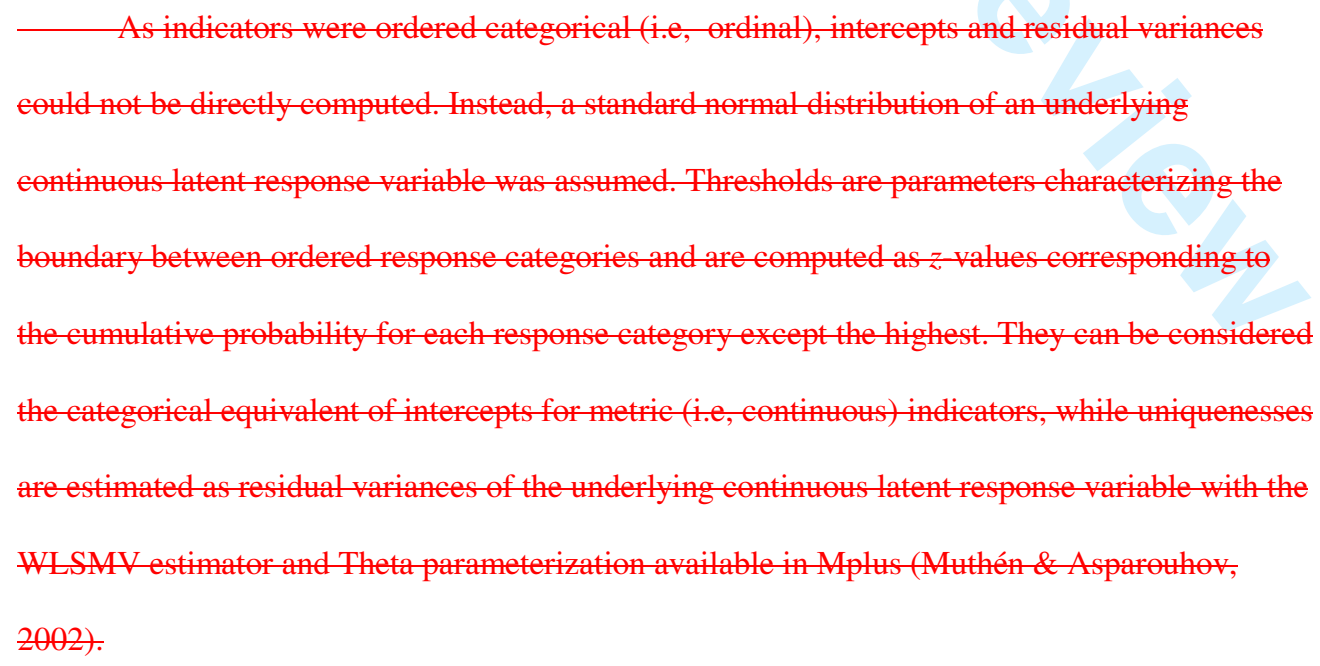


We usedset the identification constraints of invariance models to the values suggested by Muthén and Muthén (1998-2012, p. 486). When using the WLSMV estimator and Theta parameterization for observed categorical indicators, residual variances of the latent response variables for underlying the observed categorical indicators are part of the default model. In this ease, The residual variances of both groups cannot be simultaneously estimated, but the first group has residual variances fixed at one for all observed categorical indicators and in the other group the residual variances are free to be estimated with starting values of one (Muthén \& Asparouhov, 2002). The least restrictive model ('configural invariance': Model 1 ) is thus a model in which item thresholds and factor loadings are free across groups; residual variances are fixed at one in all groups; factor means are fixed at zero in all groups. Equality constraints were then added to model parameters to test different degrees of invariance. In Model 2, factor loadings were constrained to equality (but note that residual variances are still invariant due to identification issues), while in Model 3 equality of thresholds was added. Note that in this latter model we also freed residual variances and latent means in one group. In Model 4, the residual variances of the latent observed variables in both groups were fixed at 1. Latent means invariance was finally tested (by fixing them to zero in both groups) in Model 5.

In the comparisen of invariance models,__ When comparing statistical models we considered the-more parsimonious modelmodels to be supported by as preferable if there was a difference in CFI between the fit of models of less than .01 on the CFI (Chen, 2007) or a difference in RMSEA of less than .015 (Chen, 2007). Since Marsh (2007) noted that some indices (e.g., TLI and RMSEA) incorporate a penalty for lack of parsimony so that the more parsimonious model fits data better than a less parsimonious model (i.e., the gain in parsimony is greater than the loss in fit), we also considered the more parsimonious model to be supported by 
a TLI or RMSEA which was as good as, or better than that for the-, a more complex model. Note that the Bayesian Information Criterion (BIC) contains a more appropriate parsimony penalty for comparing the CFA and ESEM models, but it cannot be computed when using WLSMV estimation, since it needs the log-likelihood value, which can be obtained only through maximum likelihood estimation.

\section{Results}

Formatted $S D Q$ Factor Structure

Results of the CFAs and ESEMs for mothers and fathers are reported in Table 1.

Formatted: English (U.K.)

Formatted

Formatted: English (U.K.)

[Table 1]

Among the CFA models, the model specifying five correlated factors and a positive construal method factor (Model 14 in Table 1) had the best fit for both mothers and fathers, but with CFI and TLI substantially (i.e., > .01) lower than optimal values for the father model. Modification indices suggested that the lack of fit could be ascribed to significant cross-loadings on substantive factors and, even more problematic-problematically for the interpretation of the model, to significant loadings on the method factor of non-positive items.

As pointed out in the introduction, in a CFA framework the post-hoc specification of crossloadings only grounding on modification indices might be problematic in terms of the generalization of results. Hence, we opted for ESEM. The 5-and 6-factor models-model had the best fit among the ESEM models, and since the difference in fit indices did not meet the criteria stated above, we chose the more parsimonious one. Hence, we concluded that the 5-factor ESEM 
model should be used in subsequent invariance tests. Note however that an adequate fit of an | ESEM model does not necessarily mean what Sass and Schmitt (2010) call an-" "approximate simple structure", i.e., that each item has a substantial loading on one factor and negligible loadings (i.e., $<|.30|$ ) on the others (cross-loadings). The tableTable 5 in Section 4 of the Supporting Information shows this is not the case, and the presence of substantial cross-loadings explains the higher fit of the ESEM model with respect to the CFA 5-correlated-factor model. One scale which appears problematic is HYP as in (for both parents) two items $(2,10)$ had Formatted: Font: Times New Roman, 12 pt substantial cross-loadings on COND and two other items $(21,25)$ on PRO. Moreover, two items of PEER $(11,14)$ also loaded on PRO and one item of COND (5) also loaded on EMO.

The reliability of latent scores in ESEM models was computed as the composite reliability index (Raykov, 1997). Values for COND were mothers $=.77$ and fathers $=.82$

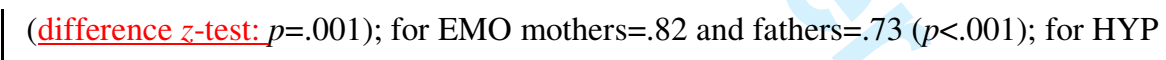
mothers $=.79$ and fathers $=.76(p=.053)$; for PEER mothers $=.66$ and fathers $=.75(p<.001)$; for PRO mothers $=.84$ and fathers $=.84(p=.627)$.

Invariance of mother and father ratings

Formatted: English (U.K.)

In testing the invariance of the 5-factor ESEM model, cross-loadings were allowed only within each source. In other words, an item rated by the mother was allowed to have non-zero crossloadings on all other mother factors, but not on father factors, and vice versa. Correlated residual variances were a priori-specified between identical mother- and father-rated items a priori (see Figure 1). 
However, the inspection of parameters representing factor means differences in Model 4 revealed that fathers tended to endorse higher scores in COND (standardized coefficient $=.13, p$ $=.009), \operatorname{HYP}(.14, p=.001), \operatorname{EMO}(.16, p=.002)$ and that mothers tended to endorse higher scores in PRO (.10, $p=.046)$. No difference was observed in PEER $(.02, p=.743)$.

It must be noted that Mplus does not allow constraints to be placed on the variance of ESEM factors in single-group analyses. As our model was equivalent to a single-group ESEM model with 50 items and 10 factors (see Figure 1 and the description of the model above), this meant that the invariance of factor variances and inter-correlations could not be tested- $\underline{\text { by }}$ comparing a model with equality constraints on factor correlations against Model 4.

Inter-parent agreement on $S D Q$ scores

Table 3 reports the correlations from tests of the strict invariance model (Model 4 in Table 2).

The same factor-different source correlations (i.e., agreement between parents) were larger (range .67 to .78 , median .70) than the different factor-different source correlations (range -.20 to .28 , median absolute value .11), suggesting adequate discriminant validity. Grounding on the guidelines of Cicchetti and Sparrow (1981), the same factor-different source correlations suggested a 'good' agreement for all scales but PEER, where the agreement was 'excellent'. 


\section{Discussion}

The aim of this study was to investigate agreement and differences between mother and father reports of their child's behavioral and emotional problems as assessed by the SDQ. To address this aim, we conducted a multiple indicator (problematic behaviors) by multitrait (five latent dimensions) by multisource (mothers and fathers of the same child) invariance analysis. Demonstrating measurement invariance between mother and father ratings of the same child is necessary for studies which use parental ratings on the SDQ to draw valid conclusions about inter-rater reliability and mean score differences. In turn, this would allow to conclude researchers to draw conclusions about whether both parents provide the same information, and thus whether either can be confidently used as a single informant. Alternatively, a lack of interrater agreement and/or substantial mean score differences would suggest that mothers and fathers would be providing different perspectives and thus potentially relevant and unique information about their child's behavioral and emotional problems.

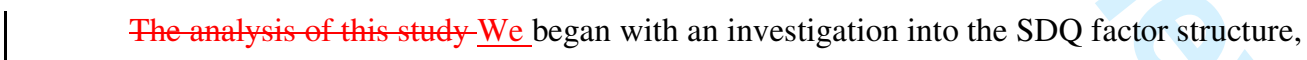
an issue which had not been conclusively addressed by previous research (see Section 1 of the Supporting Information). We found that in both parents an ESEM model allowing for non-zero cross-loadings fitted substantially better than both a 5-correlated-factor CFA model and a 5correlated-factor CFA model with an additional positive construal method factor. This means that there was n-only weak support for the model that is commonly used by researchers to compute scale scores (a 5-factor ICM-CFA model). The problem is that some items, especially in 
the HYP scale, showed a weak discriminant validity, i.e., they appeared to be indicators of more than one construct. This result has two important implications: (1) Additional work on the content and the wording of the SDQ items might improve the validity of the questionnaire; (2) If cross-loadings consistent with an ESEM approach are required to fit the data, then a simple unweighted average of the multiple indicators (based on ICM) is unlikely to provide an optimal representation of the latent construct (Marsh et al., 2009). Hence, the results of this study suggest if the SDQ is part of a Structural Equation Model (e.g., a latent growth model to investigate systematic change in childrens'children's behavior), then the analyses will be more appropriately carried out via use of an ESEM approach than a traditional ICM-CFA approach. However, it must be noted that this does not mean that the ESEM approach should always replace the corresponding CFA approach. When a more parsimonious CFA model fits the data as well as the ESEM model does, then the CFA should be used. And even when the CFA does not adequately fit the data, if items are hypothesized to be complex and to measure multiple aspects of the construct under study, cross-loadings can be specified a priori and their plausibility and consistency tested while still using a CFA framework (Booth \& Hughes, 2014). However, when there are no theoretical grounds to support the specification of cross-loadings, and thus when $\underline{\text { researchers are obliged to rely on post-hoc modification indices, ESEM models might provide a }}$ viable alternative to CFA.

With the preferable factor structure of the SDQ established, the central aim of this paper could then be addressed. The results of the parent-rating invariance analysis showed that a 5factor ESEM model of the SDQ was reasonably invariant across parents. Although some differences in scale internal consistency were found when considering scores separately for mothers and fathers (see Table 2), the negligible loss of fit for the invariance model that 
constrained to equality factor loadings, thresholds, and residual variances suggested negligible differences in the reliability of mother and father scores.

The demonstration of the invariance of item loadings and thresholds then allowed a valid evaluation of inter-parent agreement and of the invariance of the factor means between sources. Estimates of the inter-parent agreement were all 'good' and one 'excellent'. Further, the level of agreement did not differ between internalizing and externalizing behaviors. This is finding is inconsistent not only with previous research on the SDQ (Davé et al., 2008; Mellor et al., 2011), but also with research on other psychological measures such as the Big Five personality types (higher agreement on more easily observable traits such as Conscientiousness and Openness to Experience than on atan internal, less observable trait such as Neuroticism; Tackett, 2011) and parent-child relationships (higher agreement for conflict than for closeness, Driscoll \& Pianta, 2011).

In contrast, a finding that was consistent with literature was that fathers' scores were higher than mothers' for COND, HYP and EMO and lower for PRO. While future research should shed light on the reasons for these results, they suggest that mothers and fathers provide different and unique perspectives in reporting on their child's behavioral and emotional problems, and thus, whenever possible, they should be-both be collected. Note that this does not necessarily mean that scores should be averaged. As suggested by Tackett (2011), when utilizing mean-level ratings to predict later behavior or to guide assessment and treatment, the presence of discrepancies on child's personality ratings can create confusion, as it might be an indicator of conflict in the family system and might point to other sources of clinically relevant information that could be useful in case conceptualization and treatment planning. 
Limitations and future research

Some limitations of this study must be acknowledged. First, although the families in the FCCCstudy were fairly representative of the areas they were sampled, (Malmberg et al., 2005) the subsample here (both mother and father ratings of the same child) excluded single-parent families a priori. Stable couples were likely to be more advantaged than single-parent or restructured families. As child problem behavior is more prevalent among disadvantaged families, so the range of the scores here reaches clinical levels in no more than $3 \%$ of cases (see also Stein et al., 2012 and Supporting Information, Section 2, Table 4).

Substantively, although our findings suggest that mother and father ratings do not seem to be fully interchangeable, the results at this point might be considered specific to: (1) cultural context (limited to UK), (2) sampling of parent dyads (no data on non-stable couples was considered), (3) age range (limited to 51 months). Given the worldwide availability of the SDQ, it would be useful to repeat the analyses reported in this paper in different cultural contexts, with non-stable couples and with other age ranges.

Methodologically, the exploration and invariance aspects of the analyses have been

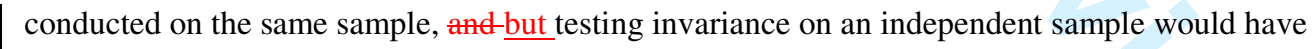
provided stronger evidence. As reported by Burns et al. (2013), some limitations of the ESEM multiple indicaterindicators by multitrait by multisource model must also be pointed out. This model cannot separate variability in the individual behavior ratings into latent source and latent trait effects. In other words, it cannot determine how much of the variance in the behavior ratings for mothers and fathers is trait variance, source variance, and residual. If -answering research questions requires the specification of latent source and trait factors in order to relate these factors to predictors and outcomes, then a 'multiple indicator by correlated trait by correlated 
method minus one model' would allow for a better examination of trait and source effects (see Eid, Lischetzke \& Nussbeck, 2006). Moreover, Dumenci, Achenbach and Windle (2011) suggested model to measure context-specific and cross-contextual effects in multiple source rating scales.

Future studies could also include other ways in which invariance could be assessed, for example if mothers and fathers rate the behaviors of boys and girls differently. Several studies have found an interaction between the gender of parent and the gender of the rated child, whereby mothers report greater problems for sons than do fathers, and fathers report more problems for daughters than do mothers (Stanger \& Lewis, 1993; Duhig et al., 2000). Jensen et al. (1988) reported that mothers and fathers differed significantly in their ratings of their sons' behavioral problems, but not their daughters', with mothers reporting more problems for their sons., but other studies (e.g., Achenbach, Howell, Quay \& Connors, 1991; Stanger \& Lewis, 1993) have found no parent-gender by child-gender interaction in ratings of behavioral problems. For the SDQ, Davé et al. (2008) found that fathers were significantly more likely to report conduct problems, compared to mothers, among their daughters, while Mellor et al. (2011) reported that mothers endorsed significantly higher scores than fathers for prosocial behaviors for their sons. In principle it is possible to specify an ESEM-within-CFA model that allows to partitionpartitions latent mean differences into tests of rater, child gender, and interaction effects (see,e.g., Marsh, Nagengast \& Morin, 2012). In this study however, while all scoring categories were endorsed at least once for each item in the total sample used for the analyses (see Section 2, Table 2 of the Supporting Information), we found that in some items the highest scoring category was never endorsed in either the boy or girl subgroups. This would not have allowed us to test 
such models without resorting to data transformations. For example, by collapsing the two highest scoring categories.

\section{Conclusions}

In this paper we have showedshown the usefulness of ESEM in investigating interparent agreement on the SDQ. Results led to the conclusion that although mothers and fathers report on the same problems, they do not necessarily report the same level of problems (fathers had a tendency to report more difficulties and fewer strengths). This suggests that when possible, ratings from both parents should be collected as they provide unique information on their child's behavioral and emotional problems.

\section{References}

Formatted

Achenbach, T. M., McConaughy, S. H., \& Howell, C. T. (1987). Child-adolescent behavioral and emotional problems: Implications of cross-informant correlations for situational specificity. Psychological Bulletin, 101, 213-232. doi:10.1037-0033-2909.101.2.213

Achenbach, T. M., Howell, C. T., Quay, H. C., \& Connors, C. K.(1991). National survey of problems and competencies among four- to sixteen-year olds: Parents' reports for normative and clinical samples. Monographs of the Society for Research in Child Development, 56 ,711. Available at http://www.jstor.org/stable/1166156 [January 31stNovember 23rd, 2014].

Asparouhov, T., \& Muthén, B. (2009). Exploratory structural equation modeling. Structural Equation Modeling, 16, 397-438. doi: 10.1080/10705510903008204

Asparouhov, T., \& Muthén, B. (2010). Weighted least squares estimation with missing data. Available online at: http://www.statmodel.com/download/GstrucMissingRevision.pdf [January 31stNovember 23rd, 2014]. 
Bentler, P.M. (1990). Comparative fit indexes in structural models. Psychological Bulletin, 107, 238-246. doi: 10.1037/0033-2909.107.2.238-

Booth, T., \& Hughes, D. J. (2014). Exploratory Structural Equation Modeling of Personality Data. Assessment, 21(3), 260-271. doi: 10.1177/1073191114528029

Browne, M.W. (2001). An overview of analytic rotation in exploratory factor analysis. Multivariate Behavioral Research, 36, 111-150. doi: 10.1207/S15327906MBR3601_05

Burns, G. L., Desmul, C., Walsh, J. A., Silpakit, C., \& Ussahawanitchakit, P. (2009). A multitrait (ADHD-IN, ADHD-HI, ODD toward adults, academic and social competence) by multisource (mothers and fathers) evaluation of the invariance and convergent/discriminant validity of the Child and Adolescent Disruptive Behavior Inventory with Thai adolescents. Psychological Assessment, 21(4), 635-641. doi: 10.1037/a0016953.

Burns, G. L., Walsh, J. A., Severa, M., Lorenzo-Seva, U., Cardo, E., \& Rodríguez-Fornells, A. (2013). Construct validity of ADHD/ODD rating scales: Recommendations for the evaluation of forthcoming DSM-V ADHD/ODD scales. Journal of Abnormal Child Psychology, 41, 15-26. doi: 10.1007/s10802-012-9660-5-

Chen, F. F. (2007). Sensitivity of goodness of fit indexes to lack of measurement invariance. Structural Equation Modeling, 14, 464-504. doi: 10.1080/10705510701301834. Church, A. T., Burke, P. J. (1994). Exploratory and confirmatory tests of the Big Five and Tellegen's three-and four- dimensional models. Journal of Personality and Social Psychology, 66, 93-114. doi: 10.1037/0022-3514.66.1.93-

Cicchetti, D. V. \& Sparrow, S. A. (1981). Developing criteria for establishing interrater reliability of specific items: Applications to assessment of adaptive behavior. American Journal of Mental Deficiency, 86, 127-137. 
Davé, S., Nazareth, I., Senior, R., \& Sherr, L. (2008). A Comparison of father and mother report of child behaviour on the Strengths and Difficulties Questionnaire. Child Psychiatry \& Human Development, 39, 399-413. doi: 10.1007/s10578-008-0097-6-

De Los Reyes, A. (2008). Whose depression relates to discrepancies? Testing relations between informant characteristics and informant discrepancies from both informants' perspectives. Psychological Assessment, 20, 139-149. doi: 10.1037/1040-3590.20.2.139.

De Los Reyes, A., \& Kazdin, A. E. (2005). Informant discrepancies in the assessment of childhood psychopathology: A critical review, theoretical framework, and recommendations for further study. Psychological Bulletin, 131, 483-509. doi:10.1037/0033-2909.131.4.483

Dickey, W., C., \& Blumberg, S., J. (2004). Revisiting the factor structure of the Strengths and Difficulties Questionnaire: United States, 2001. Journal of the American Academy of Child and Adolescent Psychiatry, 43, 1159-1167. doi: 10.1097/01.chi.0000132808.36708.a9.

Driscoll, K., \& Pianta, R. C. (2011). Mothers' and fathers' perceptions of conflict and closeness in parent-child relationships during early childhood. Journal of Early Childhood and Infant Psychology, 7, 1-20.

Duhig, A.M., Renk, K., Epstein, M.K., \& Phares, V. (2000). Inter-parental agreement on internalizing, externalizing, and total behavior problems: A meta-analysis. Clinical Psychology: Science and Practice, 7, 435- 453. doi: 10.1093/clipsy.7.4.435.

Dumenci, L., Achenbach, T. M., \& Windle, M. (2011). Measuring context-specific and crosscontextual components of hierarchical constructs. Journal of Psychopathology and Behavioral Assessment, 33, 3-10. doi: 10.1007/s10862-010-9187-4. 
Eid, M., Lischetzke, T., \& Nussbeck, F. W. (2006). Structural equation modeling for multitraitmultimethod data. In M. Eid \& E. Diener (Eds.), Handbook of multimethod measurement in psychology (pp. 283-299). Washington, DC: American Psychological Association.

Goodman, R. (1994). A modified version of the Rutter parent questionnaire including items on children's strengths: A research note. Journal of Child Psychology and Psychiatry, 35, 1483-1494. doi: 10.1111/j.1469-7610.1994.tb01289.x-

Jensen, P.S., Traylor, J., Xenakis, S.N., \& Davis, H. (1988). Child psychopathology rating scales and interrater agreement: I. Parents' gender and psychiatric symptoms. Journal of the American Academy of Child \& Adolescent Psychiatry. 27, 442-450. doi: 10.1097/00004583198807000-00012:

Liles, B. D., Newman, E., Lagasse, L. L., Derauf, C., Shah, R., Smith, L. M., ... Lester, B. M. (2012). Perceived child behavior problems, parenting stress, and maternal depressive symptoms among prenatal methamphetamine users. Child Psychiatry and Human Development, 43, 943-957. doi:10.1007/s10578-012-0305-2

MacCallum, R.C., Roznowski, M., \& Necowitz, L.B. (1992). Model modifications in covariance structure analysis: The problem of capitalization on chance. Psychological Bulletin, 111(3), 490-504. doi: 10.1037/0033-2909.111.3.490

Malmberg, L.-E., Davies, B., Walker, J., Barnes, J., Sylva, K., Stein, A., \& Leach, P. (2005). The Families, Children and Child Care (FCCC) study in relation to area characteristics: Recruitment and sample description. Available online at: http://www.familieschildrenchildcare.org/fccc_static_PDFs/fccc_sample_recruit.pdf [January 31stNovember 23rd, 2014]. 
Marsh, H. W. (2007). Application of confirmatory factor analysis and structural equation modeling in sport/exercise psychology. In G. Tenenbaum \& R. C. Eklund (Eds.), Handbook of sport psychology (3rd ed., pp. 774 -798). Hoboken, NJ: Wiley.

Marsh, H. W., Muthén, B., Asparouhov, T., Lüdtke, O., Robitzsch, A., Morin, A. J. S., \& Trautwein, U. (2009). Exploratory structural equation modeling, integrating CFAand EFA: Application to students' evaluations of university teaching. Structural Equation Modeling: A Multidisciplinary Journal, 16(3), 439-476. doi:10.1080/10705510903008220

Marsh, H. W., Nagengast, B., Morin, A. J. S. (2012). Measurement invariance of big-five factors over the life span: ESEM tests of gender, age, plasticity, maturity, and La Dolce Vita effects. Developmental Psychology. 49, 1194-1218. doi: 10.1037/a0026913.

Marsh, H. W., \& Grayson, D. (1995). Latent variable models of multitrat-multimethod data. In Hoyle, R.H (ed.) Structural equation modelling: Concepts, issues and applications. 177-198. Thousand Oaks, Ca, US: Sage Publications.

Mascendaro, P. M., Herman, K. C., \& Webster-Stratton, C. (2012). Parent discrepancies in ratings of young children's co-occurring internalizing symptoms. School Psychology Quarterly, 27, 134-143. doi:10.1037/a0029320

McCrory, C., \& Layte, R. (2012). Testing competing models of the Strengths and Difficulties Questionnaire's (SDQ's) factor structure for the parent-informant instrument. Personality and Individual Differences, 52, 882-887. doi: 10.1016/j.paid.2012.02.011.

Mellor, D., Wong, J., \& Xu, X. (2011). Inter-parent agreement on the Strengths and Difficulties Questionnaire: A Chinese study. Journal of Clinical Child \& Adolescent Psychology, 40, 890-896. doi: 10.1080/15374416.2011.614580. 
Meredith, W. (1993). Measurement invariance, factor analysis and factorial invariance.

Moreno, J., Silverman, W. K., Saavedra, L. M., \& Phares V. (2008). Fathers' ratings in the assessment of their child's anxiety symptoms: a comparison to mothers' ratings and their associations with paternal symptomatology. Journal of Family Psychology, 22, 915-919. doi: 10.1037/a0014097-

Muthén, B. O., \& Asparouhov, T. (2002). Latent variable analysis with categorical outcomes: multiple-group and growth modeling in Mplus. Available online at: http://www.statmodel.com/download/webnotes/CatMGLong.pdf . Mplus Web Notes: No.4. [January 31st[November 23rd, 2014].

Muthén, L. K., \& Muthén, B. O. (1998-2012). Mplus user's guide. 7thEdn. Los Angeles, CA: Muthén and Muthén.

Palmieri, P. A., \& Smith, G. C. (2007). Examining the structural validity of the Strengths and Difficulties Questionnaire (SDQ) in a U.S. sample of custodial grandmothers. Psychological Assessment, 19, 189-198. doi: 10.1037/1040-3590.19.2.189.

Raykov, T. (1997). Scale reliability, Cronbach's coefficient alpha, and violations of essential tauequivalence with fixed congeneric components. Multivariate Behavioral Research, 32, 329353. doi:10.1207/s15327906mbr3204_2-

Sanne, B., Torsheim, T., Heiervang, E., \& Stormark, K. M. (2009). The Strengths and Difficulties Questionnaire in the Bergen Child Study: A conceptually and methodically motivated structural analysis. Psychological Assessment, 21, 352-364. doi: 10.1037/a0016317. 
Sass, D. A., \& Schmitt, T. A. (2010). A comparative investigation of rotation criteria within exploratory factor analysis. Multivariate Behavioral Research, 45, 73-103. doi: 10.1080/00273170903504810.

Steiger, J. H., \& Lind, J. C. (1980, May). Statistically based tests for the number of common factors. Paper presented at the annual meeting of the Psychometric Society, Iowa City, IA.

Stein, A., Malmberg, L-E., Sylva, K., Leach, P., Barnes, J., \& FCCC (2012). The influence of different forms of early childcare on children's emotional and behavioural development at school entry. Child: Care, Health \& Development, 39, 676-687. doi: 10.1111/j.13652214.2012.01421.x-

Stone, L. L., Otten, R., Engels, R. C., Vermulst, Ad A., \& Janssens, J. M. A. M. (2010).

Psychometric properties of the parent and teacher versions of the Strengths and Difficulties Questionnaire for 4- to 12-year-olds: A Review. Clinical Child and Family Psychology Review, 13, 254-274. doi: 10.1007/s10567-010-0071-2-

Stanger, C., \& Lewis, M. (1993). Agreement among parents, teachers, and children on internalizing and externalizing behavior problems. Journal of Clinical Child Psychology. 22, 107-116. doi: 10.1207/s15374424jccp2201_11.

Sylva, K., Stein, A., Leach, P., Barnes, J., Malmberg, L-E. \& FCCC team. (2007). Family and child factors related to the use of infant care: An English study. Early Childhood Research Quarterly. 22, 118-136. doi: 10.1016/j.ecresq.2006.11.003.

Tackett, J. L. (2011). Parent Informants for Child Personality: Agreement, Discrepancies, and Clinical Utility. Journal of Personality Assessment, 93(6), 539-544.

doi:10.1080/00223891.2011.608763 
Tucker, L. R. \& Lewis, C. (1973). A reliability coefficient for maximum likelihood factor analysis. Psychometrika, 38, 1-10. doi: 10.1007/BF02291170=

Yu, C. Y. (2002). Evaluating cutoff criteria of model fit indices for latent variable models with binary and continuous outcomes. Doctoral dissertation, University of California, Los Angeles. Available at: http://www.statmodel.com/download/Yudissertation.pdf [January 31stNovember 23rd, 2014]. 
Table 1 Goodness of fit of Strengths and Difficulties Questionnaire Confirmatory Factor Analysis (CFA) and Exploratory Structural Equation Modeling (ESEM) measurement models. ESEM models are bolded for ease of interpretation $(n=695)$

\begin{tabular}{|c|c|c|c|c|c|c|c|}
\hline Model & Rater & $\chi^{2}$ & $\mathrm{df}$ & CFI & TLI & RMSEA & $\mathrm{WF}$ Formatt \\
\hline \multirow[b]{2}{*}{ CFA model 1: 1 factor } & Mother & 1581.792 & 275 & .672 & .642 & .083 & 2.274 \\
\hline & Father & 1460.509 & 275 & .665 & 635 & .079 & 2.149 \\
\hline \multirow{2}{*}{$\begin{array}{l}\text { CFA model 2: } 1 \text { factor }+1 \text { Method } \\
\text { factor }\end{array}$} & Mother & 1035.771 & 265 & .806 & .781 & .065 & 1.783 \\
\hline & Father & 1028.707 & 265 & .784 & .756 & .064 & 1.752 \\
\hline \multirow{2}{*}{ CFA model 3: 2 factors uncorrelated } & Mother & 1654.304 & 275 & .654 & .622 & .085 & 2.480 \\
\hline & Father & 1821.729 & 275 & .563 & .524 & .090 & 2.586 \\
\hline \multirow{2}{*}{$\begin{array}{l}\text { CFA model 4: } 2 \text { factors uncorrelated } \\
+ \text { Method factor }\end{array}$} & Mother & 1112.929 & 265 & .787 & .759 & .068 & 1.958 \\
\hline & Father & 1221.174 & 265 & .730 & .695 & .072 & 2.043 \\
\hline \multirow{2}{*}{ CFA model 5: 2 factors correlated } & Mother & 1286.025 & 274 & .746 & .722 & .073 & 2.041 \\
\hline & Father & 1269.414 & 274 & .719 & 692 & .072 & 1.995 \\
\hline \multirow{2}{*}{ ESEM model: 2 factors } & Mother & 1081.769 & 251 & .791 & .751 & .069 & 1.728 \\
\hline & Father & 1019.188 & 251 & .783 & .741 & .066 & 1.654 \\
\hline \multirow{2}{*}{$\begin{array}{l}\text { CFA model 6: } 2 \text { factors correlated }+ \\
\text { Method factor }\end{array}$} & Mother & 1033.795 & 264 & .807 & .780 & .065 & 1.782 \\
\hline & Father & 1027.600 & 264 & .785 & .755 & .065 & 1.752 \\
\hline \multirow[b]{2}{*}{ CFA model 7: 3 factors uncorrelated } & Mother & 1348.480 & 275 & .730 & .706 & .075 & 2.370 \\
\hline & Father & 1609.014 & 275 & .624 & .589 & .084 & 2.603 \\
\hline \multirow{2}{*}{$\begin{array}{l}\text { CFA model 8: } 3 \text { factors uncorrelated } \\
+ \text { Method factor }\end{array}$} & Mother & 835.166 & 265 & .857 & .838 & .056 & 1.777 \\
\hline & Father & 1070.989 & 265 & .773 & .742 & .066 & 2.042 \\
\hline \multirow{2}{*}{ CFA model 9: 3 factors correlated } & Mother & 857.099 & 272 & .853 & .838 & .056 & 1.634 \\
\hline & Father & 939.705 & 272 & .812 & .792 & .059 & 1.695 \\
\hline \multirow{2}{*}{ ESEM model: 3 factors } & Mother & 513.351 & 228 & .928 & .906 & .042 & 1.023 \\
\hline & Father & 552.752 & 228 & .908 & .879 & .045 & 1.086 \\
\hline
\end{tabular}


Table 1 Goodness of fit of Strengths and Difficulties Questionnaire measurement models (ctd.)

\begin{tabular}{|c|c|c|c|c|c|c|c|}
\hline Model & Rater & $\chi^{2}$ & $\mathrm{df}$ & CFI & TLI & RMSEA & WF Formatted Table \\
\hline \multirow{2}{*}{$\begin{array}{l}\text { CFA model 10: } 3 \text { factors correlated }+ \\
\text { Method factor }\end{array}$} & Mother & 583.019 & 262 & .919 & .908 & .042 & $\frac{1.290}{1.0}$ \\
\hline & Father & 688.836 & 262 & .880 & .862 & .048 & 1.406 \\
\hline \multirow[b]{2}{*}{ ESEM model: $\mathbf{4}$ factors } & Mother & 387.142 & 206 & .955 & .934 & .036 & 0.850 \\
\hline & Father & 376.299 & 206 & .952 & .930 & .034 & 0.841 \\
\hline \multirow{2}{*}{$\begin{array}{l}\text { CFA model 11: } 5 \text { factors } \\
\text { uncorrelated }\end{array}$} & Mother & 1698.375 & 275 & .642 & .610 & .086 & 2.810 \\
\hline & Father & 1883.620 & 275 & .546 & .505 & .092 & 2.955 \\
\hline \multirow{2}{*}{$\begin{array}{l}\text { CFA model 12: } 5 \text { factors } \\
\text { uncorrelated + Method factor }\end{array}$} & Mother & 1175.578 & 265 & .771 & .741 & .070 & 2.259 \\
\hline & Father & 1357.412 & 265 & .692 & .651 & .077 & 2.431 \\
\hline \multirow{2}{*}{ CFA model 13: 5 factors correlated } & Mother & 621.234 & 265 & .911 & .899 & .044 & 1.327 \\
\hline & Father & 695.485 & 265 & .879 & .862 & .048 & 1.405 \\
\hline \multirow[b]{2}{*}{ ESEM model: 5 factors } & Mother & 266.020 & 185 & .980 & .967 & .025 & 0.655 \\
\hline & Father & 286.481 & 185 & .971 & .954 & .028 & 0.695 \\
\hline \multirow{2}{*}{$\begin{array}{l}\text { CFA model 14: } 5 \text { factors correlated }+ \\
\text { Method factor }\end{array}$} & Mother & 401.899 & 255 & .963 & .957 & .029 & 1.005 \\
\hline & Father & 466.906 & 255 & .940 & .930 & .035 & 1.100 \\
\hline \multirow{2}{*}{$\begin{array}{l}\text { CFA model } 15: 5 \text { factors }+1 \text { Higher } \\
\text { Order Factor uncorrelated with } \\
\text { prosocial }\end{array}$} & Mother & 1206.227 & 271 & .765 & .740 & .070 & 2.090 \\
\hline & Father & 1426.813 & 271 & .674 & .639 & .078 & 2.279 \\
\hline \multirow{2}{*}{$\begin{array}{l}\text { CFA model 16: } 5 \text { factors+ } 1 \text { Higher } \\
\text { Order Factor correlated with } \\
\text { prosocial }\end{array}$} & Mother & 708.834 & 270 & .890 & .878 & .048 & 1.462 \\
\hline & Father & 775.440 & 270 & .857 & .842 & .052 & 1.520 \\
\hline \multirow{2}{*}{ ESEM-model: 6 factors } & Mother & 208.902 & 165 & .989 & .980 & .020 & 0.560 \\
\hline & Father & 249.161 & 165 & .976 & .957 & .027 & 0.624 \\
\hline
\end{tabular}


Table 2 Goodness of fit of measurement invariance Exploratory Structural Equation Models fot the Strengths and Difficulties Questionnaire $(n=695)$

\begin{tabular}{|ccccccccccc}
\hline Invariance & & & & & & & & & & \\
ML & TH & RV & M & $\chi^{2}$ & df & CFI & TLI & RMSEA & WRMR \\
\hline Model 1 & & & X & X & 1112.411 & 945 & .980 & .974 & .016 & 0.737 \\
Model 2 & X & & X & X & 1177.236 & 1045 & .984 & .981 & .013 & 0.817 \\
Model 3 & X & X & & & 1224.117 & 1065 & .981 & .978 & .015 & 0.830 \\
Model 4 & X & X & X & & 1250.411 & 1090 & .981 & .978 & .015 & 0.851 \\
Model 5 & X & X & X & X & 1285.049 & 1095 & .977 & .974 & .016 & 0.872 \\
\hline
\end{tabular}

Note: $\mathrm{FL}=$ factor loadings; $\mathrm{TH}=$ thresholds; $\mathrm{RV}=$ residual variances; $\mathrm{M}=$ factor means; $\mathrm{Xs}$ indicate that the parameter is invariant across raters; $\mathrm{df}=$ Degrees of Freedom; $\mathrm{CFI}=$ Comparative Fit Index; TLI=Tucker-Lewis Index; RMSEA= Root-Mean-Square Error of Approximation; WRMR= Weighted Root-Mean-square Residual. 
Table 3 Multitrait by multisource factor correlation matrix from Model 4 in Table 3 for the

Strengths and Difficulties Questionnaire $(n=695)$

\begin{tabular}{|c|c|c|c|c|c|c|c|c|c|c|}
\hline & \multicolumn{5}{|c|}{ Mothers } & \multicolumn{5}{|c|}{ Fathers } \\
\hline & COND & EMO & HYP & PEER & PRO & COND & EMO & HYP & PEER & PRO \\
\hline \multicolumn{11}{|l|}{ Mothers } \\
\hline \multicolumn{11}{|l|}{ COND } \\
\hline EMO & .23 & & & & & & & & & \\
\hline HYP & .36 & .14 & & & & & & & & \\
\hline PEER & .10 & .25 & .04 & & & & & & & \\
\hline PRO & -.10 & -.10 & -.25 & -.07 & & & & & & \\
\hline \multicolumn{11}{|l|}{ Fathers } \\
\hline COND & .73 & .03 & .24 & -.09 & -.13 & & & & & \\
\hline EMO & .14 & .67 & .07 & .13 & -.20 & .28 & & & & \\
\hline HYP & .28 & .10 & .70 & .09 & -.10 & .26 & .13 & & & \\
\hline PEER & .02 & .12 & .04 & .78 & -.07 & .02 & .24 & .08 & & \\
\hline PRO & -.20 & -.12 & -.17 & -.03 & .70 & -.12 & -.17 & -.21 & -.11 & \\
\hline
\end{tabular}

Note: . Italicized coefficients are significant at $p<.01$. Bolded coefficients are inter-parent agreement coefficients; $\mathrm{COND}=$ conduct problems; $\mathrm{EMO}=$ emotional symptoms; $\mathrm{HYP}=$ hyperactivity-inattention; $\mathrm{PEER}=$ peer problems; $\mathrm{PRO}=$ prosocial behavior. 


\section{Figure caption}

Figure 1 Baseline model for the application of Exploratory Structural Equation Modeling to the invariance of the Strength and Difficulties Questionnaire measurement model between mothers and fathers. 
Figure 1

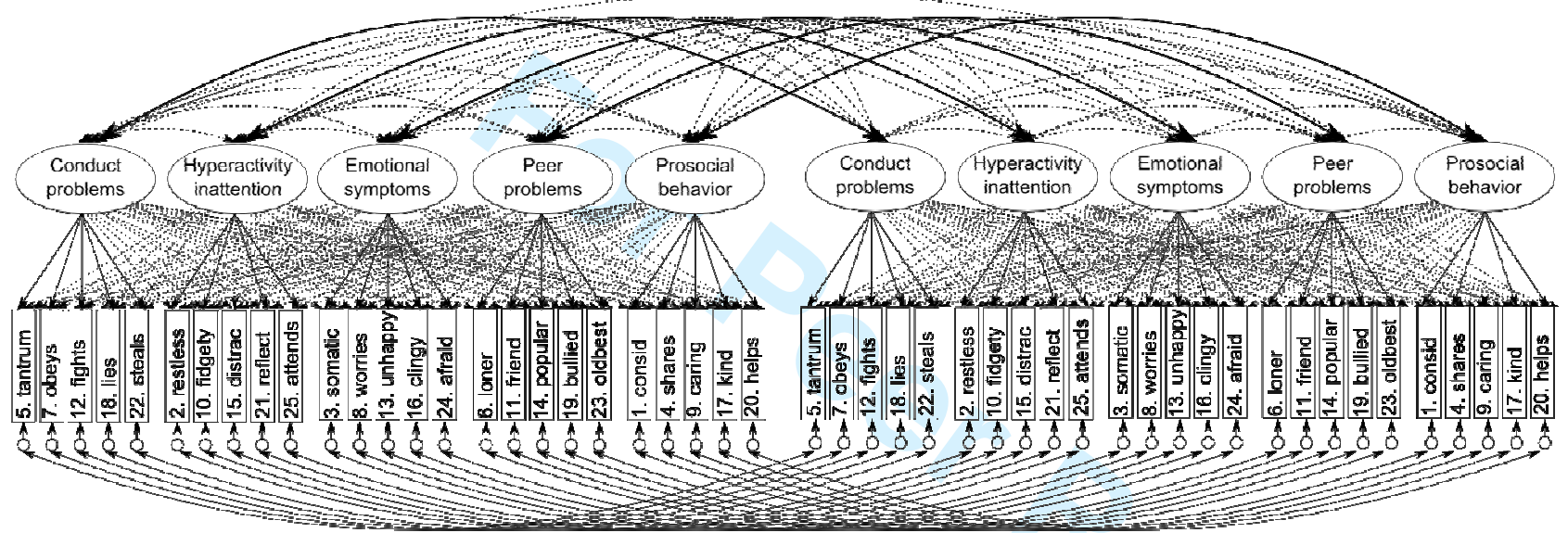

Mothers

\section{Fathers}

Note: For ease of interpretation, full lines represent inter-parent agreement correlations and target loadings while dotted lines represent different factor-same source correlations (i.e., correlations between latent constructs within each parent), different-factor different source correlations (i.e., correlations between latent constructs between parents) and cross-loadings (i.e., loadings between a priori constructs and secondary items). 


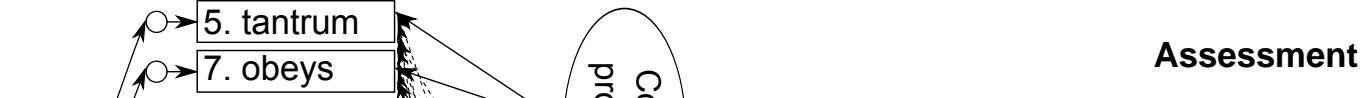




\section{A review of journal articles analyzing the factor structure of the SDQ}

Since 1999, there have been more than thirty studies examining the factor structure of the SDQ (see Table 1). This body of research is highly heterogeneous, since studies were deployed across 18 different countries, with sample sizes ranging from 128 to 71,840 participants, using parents', teachers', and individual self-reports. Moreover, these studies have differed in their factor analytic approach (Exploratory Factor Analysis [EFA], principal component analysis [PCA], confirmatory factor analysis [CFA]) and estimation methods (different kinds of maximum likelihood and weighted least squares). Attempts to replicate Goodman's original five-factor model of the SDQ (see Goodman, 2001) have yielded mixed results. Some studies have supported the five-factor model (e.g. d'Acremont \& van Der Linden, 2008; Becker et al. 2004; Capron et al. 2007;

Giannakopoulos et al. 2009; Hawes \& Dadds, 2004; He et al. 2013; Hill \& Hughes, 2007; Matsuishi et al. 2008; Niclasen et al. 2012; Rothenburger et al. 2008; Shevlin et al. 2012; Smedje et al. 1999; van Roy et al. 2008; Woerner et al. 2004; Yao et al. 2009), while others have reported failed replications (Dickey \& Blumberg, 2004; Di Riso et al. 2010; Hagquist, 2007; Haynes et al. 2013; Muris et al. 2004). Alternative models have also been suggested such as those making a theoretically plausible distinction between prosocial, internalizing (merging COND and HYP) and externalizing (merging EMO and PEER) behaviors (Haynes et al., 2013; Goodman et al., 2010). Interestingly, the results of the comparison by Goodman (2010) were inconsistent across the three versions of the SDQ (parent, teacher, self-report): Parent data supported 3 factors, teacher data 5, and self-report both 3 and 5. Goodman and colleagues (2010) concluded that when a screen was sought for low-risk samples and populations, a 3 factor implementation of the SDQ would be appropriate, but when considering high-risk populations, then the original 5 factor model had noticeable benefits in terms of discriminant validity. 
Supporting Information for SDQ Measurement Invariance

Table 1. Summary of studies since 1999 that have investigated factor structure in the Strengths and Difficulties Questionnaire

\begin{tabular}{|c|c|c|c|c|c|c|c|}
\hline Year & Authors & $\begin{array}{l}\text { Sample } \\
\text { size }\end{array}$ & Age range & Country & Rater & Analytic strategy Estimator & Results \\
\hline 1999 & Smedje et al. & 900 & $6-10$ yrs & Sweden & Parents & PCA/Varimax & $\begin{array}{l}\text { 5-factor supported with cross- } \\
\text { loadings }\end{array}$ \\
\hline 2001 & Goodman & 10438 & $5-15$ yrs & UK & $\begin{array}{l}\text { Self, Parents, } \\
\text { Teachers }\end{array}$ & EFA?/Varimax & $\begin{array}{l}\text { Expected 5-factor solutions with } \\
\text { cross-loadings }\end{array}$ \\
\hline 2001 & $\begin{array}{l}\text { Koskelainen et } \\
\text { al. }\end{array}$ & 1458 & $13-17$ yrs & Finland & Self & EFA / Varimax & $\begin{array}{l}\text { 5-factor solutions with no simple } \\
\text { structures, differences among } \\
\text { boys and girls; } 3 \text {-factor solution } \\
\text { similar across gender with no } \\
\text { simple structure }\end{array}$ \\
\hline 2003 & Muris et al. & 562 & $9-15$ yrs & Netherlands & Self, Parents & PCA/Oblimin & 5-factor $\mathrm{w} /$ cross loadings \\
\hline 2004 & Muris et al. & 1111 & $8-13$ yrs & Netherlands & Self & PCA/Oblimin & 4-factor w/ cross loadings \\
\hline 2004 & Becker et al. & 543 & $5-17$ yrs & Germany & $\begin{array}{l}\text { Parents, } \\
\text { Teachers }\end{array}$ & $\begin{array}{l}\text { CFA, } \\
\text { PCA/Varimax }\end{array}$ & $\begin{array}{l}\text { CFA: } \mathrm{AGFI}=.85, \mathrm{RMR}=.07 \text {, } \\
\text { PCA: perfect solution }\end{array}$ \\
\hline 2004 & $\begin{array}{l}\text { Dickey \& } \\
\text { Blumberg }\end{array}$ & 10367 & 4-17 yrs & US & Parents/guardian & $\begin{array}{l}\text { Cross validation } \\
\text { PCA/PROMAX } \\
\text { and CFA }\end{array}$ & $\begin{array}{l}\text { Not very neat PCA 5-factor } \\
\text { solution, better } 3 \text {-factor solution, } \\
\text { CFA used RMR and GFI }\end{array}$ \\
\hline 2004 & Hawes \& Dadds & 1359 & $4-9$ yrs & Australia & Parent & PCA/Oblimin & $\begin{array}{l}\text { 5-factor supported, with cross- } \\
\text { loadings }\end{array}$ \\
\hline 2004 & Rønning et al. & 5225 & $11-16$ yrs & Norway & Self & WLS & $\begin{array}{l}\text { Poor fit 5-factor; added CUs and } \\
\text { cross loadings }\end{array}$ \\
\hline 2004 & Woerner et al. & 930 & $6-16$ yrs & Germany & Parents & PCA/Varimax & $\begin{array}{l}\text { 5-factor supported with cross- } \\
\text { loadings }\end{array}$ \\
\hline 2005 & Kashala et al. & 1187 & $7-9$ yrs & Congo & Teachers & PCA/Varimax & 5-factor with no simple structure \\
\hline 2006 & $\begin{array}{l}\text { Van Leeuwen et } \\
\text { al. }\end{array}$ & 1086 & $4-8$ yrs & Netherlands & $\begin{array}{l}\text { Parents, } \\
\text { Teachers }\end{array}$ & $\begin{array}{l}\text { PAF/oblique, } \\
\text { CFA }\end{array}$ & $\begin{array}{l}\text { EFA 3- and 5-factor solution } \\
\text { with cross-loadings; CFA 5- } \\
\text { factor model slightly better than } \\
\text { 3-factor model }\end{array}$ \\
\hline
\end{tabular}

http://mc.manuscriptcentral.com/asmnt 


\begin{tabular}{|c|c|c|c|c|c|c|c|c|}
\hline Year & Authors & $\begin{array}{l}\text { Sample } \\
\text { size }\end{array}$ & Age range & Country & Rater & Analytic strategy & Estimator & Results \\
\hline 2007 & Capron et al. & 1400 & $13 \mathrm{yrs}$ & France & Self & PCA/Varimax & & $\begin{array}{l}\text { Not very neat, substantial cross- } \\
\text { loadings }\end{array}$ \\
\hline 2007 & Hagquist & 8838 & $12-18 \mathrm{yrs}$ & Sweden & Self & Rasch analysis & & \\
\hline 2007 & Hill \& Hughes & 784 & 6 yrs & & $\begin{array}{l}\text { Parents, } \\
\text { Teachers }\end{array}$ & CFA & & $\begin{array}{l}\text { 5-factor model marginally } \\
\text { acceptable fit with CUs for oth } \\
\text { parents and teachers }\end{array}$ \\
\hline 2007 & $\begin{array}{l}\text { Mellor \& } \\
\text { Stokes }\end{array}$ & 914 & $7-17$ yrs & Australia & $\begin{array}{l}\text { Self, Parents, } \\
\text { Teachers }\end{array}$ & CFA & $\begin{array}{l}\text { ML, ADF, } \\
\text { MLR }\end{array}$ & $\begin{array}{l}\text { Hierarchical (negative 2nd order } \\
\text { factor) w/ poor fit }\end{array}$ \\
\hline 2007 & $\begin{array}{l}\text { Palmieri \& } \\
\text { Smith }\end{array}$ & 733 & $4-16$ yrs & US & Grandmothers & CFA & MLR & $\begin{array}{l}\text { (A) Hierarchical (negative 2nd } \\
\text { order factor); (B) } 5 \text { factor model, } \\
\text { (C) } 5 \text {-factor w/ wording factor. } \\
\text { All excellent fit but } \mathrm{C} \text { better }\end{array}$ \\
\hline 2008 & $\begin{array}{l}\text { Rothernberger } \\
\text { et al. }\end{array}$ & 2406 & $7-16$ yrs & Germany & Self Parents & $\begin{array}{l}\text { CFA, } \\
\text { PCA/varimax }\end{array}$ & & 5 -factor structure \\
\hline 2008 & $\begin{array}{l}\text { d'Acremont \& } \\
\text { Van der Linden }\end{array}$ & 560 & $12-14 \mathrm{yrs}$ & Switzerland & Teachers & CFA & $\begin{array}{l}\text { WLSMV, } \\
\text { MLR }\end{array}$ & $\begin{array}{l}\text { Only RMSEA and SRMR for } \\
\text { single samples; CFI». } 80 \text { for } \\
\text { invariance }\end{array}$ \\
\hline 2008 & Du et al. & 1965 & $3-17$ yrs & China & $\begin{array}{l}\text { Self }(960), \\
\text { Parents, } \\
\text { Teachers }\end{array}$ & PCA/Varimax & 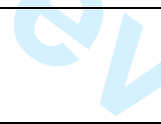 & $\begin{array}{l}\text { 5-factor solutions with no simple } \\
\text { structure in either rater }\end{array}$ \\
\hline 2008 & Matsuishi et al. & 2899 & $4-12$ yrs & Japan & Parents & EFA/Varimax & & $\begin{array}{l}\text { 5-factor structure with no simple } \\
\text { structure }\end{array}$ \\
\hline 2008 & Percy et al. & 3753 & $12 \mathrm{yrs}$ & $\begin{array}{l}\text { Northern } \\
\text { Ireland }\end{array}$ & Self & EFA/Promax & MLR & $\begin{array}{l}\text { 3- and 5-factor poor fit event } \mathrm{w} / \\
\text { CUs }\end{array}$ \\
\hline 2008 & Ruchkin et al. & 4671 & $11-15 \mathrm{yrs}$ & US & Self & $\begin{array}{l}\text { CFA, } \\
\text { PAF/Oblimin }\end{array}$ & & $\begin{array}{l}\text { Original 5-factor partially } \\
\text { supported, new 3-factor }\end{array}$ \\
\hline 2008 & Van Roy et al. & 26269 & $10-19 \mathrm{yrs}$ & Norway & $\begin{array}{l}\text { Self, Parents } \\
\text { (6645) }\end{array}$ & CFA & & $\begin{array}{l}\text { (A) 5-factor model; (B) 5-factor } \\
\text { model with CUs; (C) 5-factor } \\
\text { model with wording factor; (C) } \\
\text { batter fit; MTMM excellent fit }\end{array}$ \\
\hline
\end{tabular}




\begin{tabular}{|c|c|c|c|c|c|c|c|c|}
\hline Year & Authors & $\begin{array}{l}\text { Sample } \\
\text { size }\end{array}$ & Age range & Country & Rater & Analytic strategy & Estimator & Results \\
\hline 2009 & $\begin{array}{l}\text { Giannakopoulos } \\
\text { et al. }\end{array}$ & 1194 & $11-17$ yrs & Greece & Self & CFA & ML & $\begin{array}{l}\text { 5-factor model fitted after } \\
\text { allowing secondary loadings }\end{array}$ \\
\hline 2009 & Sanne et al. & 8999 & $7-9$ yrs & Norway & $\begin{array}{l}\text { Parents }(6430), \\
\text { Teachers }(8999)\end{array}$ & $\begin{array}{l}\text { EFA, ESEM, } \\
\text { CFA, }\end{array}$ & WLSMV & $\begin{array}{l}\text { Modestly modified version of } \\
\text { original 5-factor, good support } \\
\text { for informant invariance }\end{array}$ \\
\hline 2009 & Yao et al. & 1135 & $11-18$ yrs & China & Self & CFA & ML & $\begin{array}{l}\text { original 5-factor + hierarchical, } \\
\text { acceptable fit depending on age }\end{array}$ \\
\hline 2010 & Di Riso et al & 1394 & $8-10$ yrs & Italy & Self & CFA & WLS & $\begin{array}{l}\text { 3-factor model slightly better fit } \\
\text { than } 5 \text {-factor }\end{array}$ \\
\hline 2010 & $\begin{array}{l}\text { Goodman A. et } \\
\text { al. }\end{array}$ & 18222 & $5-16$ yrs & UK & $\begin{array}{l}\text { Self, Parents, } \\
\text { Teachers }\end{array}$ & CFA & WLSMV & $\begin{array}{l}\text { (A) 5-factor, (B) 5-factor w/ 2nd } \\
\text { order, (C) 3-factor; B better } \\
\text { model across informants but } \\
\text { with CUs }\end{array}$ \\
\hline 2010 & $\begin{array}{l}\text { Mansbach- } \\
\text { Kleinfeld et al. }\end{array}$ & 611 & $14-17$ yrs & Israel & Self, Mothers & EFA/CFA & & $\begin{array}{l}\text { Failed to replicate original 5- } \\
\text { factor structure }\end{array}$ \\
\hline 2010 & Stone et al. & Review & - & - & $\begin{array}{l}\text { Parents, } \\
\text { Teachers }\end{array}$ & & & $\begin{array}{l}\text { Most studies confirmed 5-factor } \\
\text { structure }\end{array}$ \\
\hline 2011 & Richter et al. & 5379 & $15 \mathrm{yrs}$ & Norway & Self & CFA & DWLS & $\begin{array}{l}\text { Optimal fit 5-factor structure } \\
\text { across ethnic groups }\end{array}$ \\
\hline 2011 & $\begin{array}{l}\text { Van de Looji- } \\
\text { Jansen et al. }\end{array}$ & 11881 & $11-16 \mathrm{yrs}$ & Netherlands & Self & EFA/CFA & WLSM & $\begin{array}{l}\text { Original 5-factor model with } \\
\text { CUs and new 4-factor model }\end{array}$ \\
\hline 2012 & Essau et al. & 2418 & $12-17$ yrs & $\begin{array}{l}\text { Germany, } \\
\text { Cyprus, } \\
\text { England, } \\
\text { Sweden, } \\
\text { Italy }\end{array}$ & Self & CFA & MLR & $\begin{array}{l}\text { Mixed results depending on } \\
\text { country. Similar fit 3- and 5- } \\
\text { factor on total sample, poor fit } \\
\text { on national samples except } \\
\text { Cyprus }\end{array}$ \\
\hline 2012 & $\begin{array}{l}\text { McCrory \& } \\
\text { Layte }\end{array}$ & 8514 & 9 yrs & Ireland & Parent & CFA & WLSMV & $\begin{array}{l}\text { (A) 3-factor model, (B) } 5 \text { factor } \\
\text { model, (C) } 5 \text {-factor w/ wording } \\
\text { factor, (D) Hierarchical } \\
\text { (negative } 2 \text { nd order factor); (C) } \\
\text { better fitting }\end{array}$ \\
\hline
\end{tabular}




\begin{tabular}{|c|c|c|c|c|c|c|c|c|}
\hline Year & Authors & $\begin{array}{l}\text { Sample } \\
\text { size }\end{array}$ & Age range & Country & Rater & Analytic strategy & Estimator & Results \\
\hline 2012 & Niclasen et al. & 71840 & $5-12$ yrs & Denmark & $\begin{array}{l}\text { Parents, } \\
\text { Teachers }\end{array}$ & PCA/Promax & & 5-factor w/ cross loadings \\
\hline 2012 & Shevlin et al. & 202 & $7.17 \mathrm{yrs}$ & $\begin{array}{l}\text { Northern } \\
\text { Ireland }\end{array}$ & Self, counsellor & CFA MTMM & WLSMV & $\begin{array}{l}\text { Original 5-factor structure w/ } \\
\text { cross-loadings to reach } \\
\text { acceptable fit }\end{array}$ \\
\hline 2013 & $\begin{array}{l}\text { Gómez-Beneyto } \\
\text { et al. }\end{array}$ & 6773 & 4-15 yrs & Spain & Informants & $\begin{array}{l}\text { EFA (ULS, } \\
\text { PROMIN), CFA }\end{array}$ & DWLS & $\begin{array}{l}\text { 3- and 5-factor structure but no } \\
\text { expected simple structure from } \\
\text { EFA; adequate and similar fit for } \\
\text { 3- and 5-factors }\end{array}$ \\
\hline 2013 & Haynes et al. & 128 & $9-14$ yrs & Australia & $\begin{array}{l}\text { Self (with } \\
\text { modified items) }\end{array}$ & $\begin{array}{l}\text { PCA/Varimax } \\
\text { and Oblimin }\end{array}$ & & $\begin{array}{l}\text { 5-factor wth no simple structure; } \\
\text { 3-factor but idiosyncratic } \\
\text { solution (see Table } 6 \text { ) }\end{array}$ \\
\hline 2013 & He et al. & 6843 & $13-18$ yrs & US & Parents & CFA & WLSMV & $\begin{array}{l}\text { Original } 5 \text {-factor structure } \\
\text { adequate }\end{array}$ \\
\hline 2013 & Stone et al. & 1484 & $9-12$ yrs & Netherlands & Mothers & CFA & WLSMV & 5-factor structure confirmed \\
\hline 2013 & Niclasen et al. & 63615 & $5-7$ yrs & Denmark & $\begin{array}{l}\text { Parents, } \\
\text { Teachers }\end{array}$ & CFA & WLS & $\begin{array}{l}5 \text {-factor structure }+ \text { second order } \\
\text { factors }\end{array}$ \\
\hline 2013 & Ezpeleta et al. & 622 & 3 yrs & Spain & $\begin{array}{l}\text { Parents, } \\
\text { Teachers }\end{array}$ & CFA & WLSMV & 5-factor structure confirmed \\
\hline
\end{tabular}

Note: PCA: Principal Components Analysis; EFA = Exploratory Factor Analysys; CFA = Confrimatory Factor Analysis; ESEM = Exploratory Structural Equation Modeling; ULS = Unweighted Least Squares; WLS = Weighted Least Squares; ML = Maximum Likelihood; ADF =

Asymptotic Distribution Free; MLR = robust Maximum Likelihood; WLSMV = Weighted Least Squares Mean and Variance Adjusted; DWLS = Diagonally Weighted Least Squares 


\section{Descriptive statistics for item and scale scores}

Table 2 Descriptive statistics (proportions) for the Strengths and Difficulties Questionnaire items $(n=$ 695) on raw data (i.e., reverse item scores not reversed)

\begin{tabular}{|c|c|c|c|c|c|c|c|c|c|c|}
\hline \multirow[b]{2}{*}{ Item } & \multirow[b]{2}{*}{ Content } & \multirow[b]{2}{*}{ Scale } & \multicolumn{4}{|c|}{ Mothers } & \multicolumn{4}{|c|}{ Fathers } \\
\hline & & & missing & 0 & 1 & 2 & missing & 0 & 1 & 2 \\
\hline sdq01 & consid & PRO & .01 & .01 & .42 & .56 & .01 & .02 & .52 & .45 \\
\hline sdq02 & restles & HYP & $<.01$ & .51 & .40 & .09 & $<.01$ & .42 & .41 & .16 \\
\hline sdq03 & somatic & EMO & .01 & .85 & .13 & .01 & $<.01$ & .86 & .12 & .02 \\
\hline sdq04 & shares & PRO & $<.01$ & .03 & .58 & .39 & $<.01$ & .06 & .56 & .39 \\
\hline sdq05 & tantrum & COND & $<.01$ & .51 & .39 & .10 & $<.01$ & .45 & .42 & .13 \\
\hline sdq06 & loner & PEER & $<.01$ & .70 & .25 & .05 & .01 & .69 & .27 & .03 \\
\hline sdq07 & obeys (r) & COND & $<.01$ & .05 & .60 & .36 & $<.01$ & .05 & .58 & .36 \\
\hline sdq08 & worries & EMO & $<.01$ & .88 & .11 & .01 & $<.01$ & .89 & .09 & .01 \\
\hline sdq09 & caring & PRO & $<.01$ & .02 & .29 & .69 & .01 & .01 & .28 & .70 \\
\hline sdq10 & fidgety & HYP & .01 & .66 & .27 & .06 & .01 & .64 & .27 & .08 \\
\hline sdq11 & friend (r) & PEER & $<.01$ & .02 & .12 & .86 & $<.01$ & .03 & .13 & .84 \\
\hline sdq12 & fights & COND & $<.01$ & .90 & .09 & $<.01$ & $<.01$ & .89 & .10 & .01 \\
\hline sdq13 & unhappy & EMO & $<.01$ & .92 & .06 & .02 & $<.01$ & .90 & .08 & .02 \\
\hline sdq14 & popular (r) & PEER & $<.01$ & $<.01$ & .17 & .83 & .01 & .01 & .16 & .83 \\
\hline sdq15 & distrac & HYP & $<.01$ & .47 & .45 & .07 & .01 & .43 & .45 & .10 \\
\hline sdq16 & clingy & EMO & .01 & .51 & .41 & .08 & $<.01$ & .46 & .44 & .10 \\
\hline sdq17 & kind & PRO & .01 & $<.01$ & .26 & .73 & .01 & .01 & .28 & .70 \\
\hline sdq18 & lies & COND & $<.01$ & .82 & .17 & .01 & .02 & .78 & .19 & .01 \\
\hline sdq19 & bullied & PEER & .01 & .91 & .07 & .01 & .01 & .92 & .07 & .01 \\
\hline sdq20 & helpout & PRO & .01 & .03 & .45 & .51 & .01 & .05 & .48 & .46 \\
\hline sdq21 & reflect (r) & HYP & .01 & .11 & .73 & .15 & .01 & .14 & .63 & .21 \\
\hline sdq22 & steals & COND & $<.01$ & .96 & .04 & $<.01$ & $<.01$ & .96 & .03 & $<.01$ \\
\hline sdq23 & oldbest & PEER & .01 & .72 & .23 & .04 & .01 & .73 & .22 & .03 \\
\hline sdq24 & afraid & EMO & $<.01$ & .74 & .22 & .04 & $<.01$ & .69 & .27 & .04 \\
\hline sdq25 & attends (r) & HYP & $<.01$ & .10 & .55 & .34 & .01 & .12 & .59 & .29 \\
\hline
\end{tabular}

Note: $(\mathrm{r})=$ reverse item; $\mathrm{COND}=$ conduct problems; $\mathrm{EMO}=$ emotional symptoms; $\mathrm{HYP}=$ hyperactivity-inattention; $\mathrm{PEER}=$ peer problems; $\mathrm{PRO}=$ prosocial behavior. 
Table 3 Descriptive statistics for observed scale scores $(n=695)$

\begin{tabular}{lccccccc}
\hline Scale & Valid & Min & Max & $M$ & SD & SK & $K U$ \\
\hline & & & \multicolumn{5}{c}{ Mothers } \\
PRO & 680 & 2 & 10 & 7.79 & 1.67 & -0.57 & -0.24 \\
COND & 688 & 0 & 6 & 1.60 & 1.32 & 0.72 & 0.15 \\
EMO & 684 & 0 & 9 & 1.25 & 1.45 & 1.64 & 3.45 \\
HYP & 681 & 0 & 10 & 3.30 & 2.19 & 0.60 & -0.01 \\
PEER & 682 & 0 & 8 & 1.09 & 1.33 & 1.61 & 3.37 \\
Problems & 655 & 0 & 26 & 7.15 & 4.12 & 1.03 & 1.66 \\
& & & & & & & \\
PRO & 676 & 2 & 10 & 7.58 & 1.73 & -0.43 & -0.45 \\
COND & 678 & 0 & 8 & 1.73 & 1.42 & 0.90 & 0.87 \\
EMO & 688 & 0 & 9 & 1.37 & 1.43 & 1.41 & 2.71 \\
HYP & 675 & 0 & 10 & 3.59 & 2.30 & 0.41 & -0.33 \\
PEER & 673 & 0 & 8 & 1.09 & 1.34 & 1.53 & 2.61 \\
Problems & 648 & 0 & 26 & 7.80 & 4.33 & 0.95 & 1.58 \\
\hline N & & & & & & \\
\end{tabular}

Note: $\mathrm{PRO}=$ prosocial behavior; $\mathrm{COND}=$ conduct problems; $\mathrm{EMO}=$ emotional symptoms; $\mathrm{HYP}=$ hyperactivity-inattention; $\mathrm{PEER}=$ peer problems; Problems = total problem score is generated by summing the scores of the four problem subscales (excluding the prosocial behaviour subscale) 
We also checked for abnormal and borderline score thresholds are for the total problem score, as reported in Stein et al. (2012): for parent reports, abnormal scores are 17+, borderline scores are 1416. Details of the frequency distribution of total problems scores for mothers and fathers are reported in Table 4.

Table 4 Frequency distribution of total problems scores for mothers and fathers

\begin{tabular}{|c|c|c|c|c|c|c|c|c|c|}
\hline \multirow[b]{2}{*}{$\begin{array}{c}\text { Classification } \\
\text { of scores }{ }^{a}\end{array}$} & \multirow[b]{2}{*}{ Score } & \multicolumn{4}{|c|}{ Mothers } & \multicolumn{4}{|c|}{ Fathers } \\
\hline & & $f$ & $P$ & $\begin{array}{l}\text { Valid } \\
P \\
\end{array}$ & $\begin{array}{c}\text { Cumulative } \\
P\end{array}$ & $f$ & $P$ & $\begin{array}{c}\text { Valid } \\
P\end{array}$ & $\begin{array}{c}\text { Cumulative } \\
P\end{array}$ \\
\hline \multirow{14}{*}{$\begin{array}{l}\text { Normal } \\
\text { scores }\end{array}$} & 0 & 6 & .01 & .01 & .01 & 9 & .01 & .01 & .01 \\
\hline & 1 & 24 & .03 & .04 & .05 & 17 & .02 & .03 & .04 \\
\hline & 2 & 39 & .06 & .06 & .11 & 30 & .04 & .05 & .09 \\
\hline & 3 & 47 & .07 & .07 & .18 & 36 & .05 & .06 & .14 \\
\hline & 4 & 59 & .08 & .09 & .27 & 53 & .08 & .08 & .22 \\
\hline & 5 & 79 & .11 & .12 & .39 & 62 & .09 & .10 & .32 \\
\hline & 6 & 77 & .11 & .12 & .51 & 63 & .09 & .10 & .42 \\
\hline & 7 & 60 & .09 & .09 & .60 & 67 & .10 & 10 & .52 \\
\hline & 8 & 58 & .08 & .09 & .69 & 59 & .08 & .09 & .61 \\
\hline & 9 & 51 & .07 & .08 & .76 & 62 & .09 & .10 & .71 \\
\hline & 10 & 32 & .05 & .05 & .81 & 50 & .07 & .08 & .78 \\
\hline & 11 & 41 & .06 & .06 & .87 & 33 & .05 & .05 & .83 \\
\hline & 12 & 20 & .03 & .03 & .91 & 26 & .04 & .04 & .88 \\
\hline & 13 & 12 & .02 & .02 & .92 & 24 & .03 & .04 & .91 \\
\hline \multirow{3}{*}{$\begin{array}{l}\text { Borderline } \\
\text { scores }\end{array}$} & 14 & 12 & .02 & .02 & .94 & 11 & .02 & .02 & .93 \\
\hline & 15 & 10 & .01 & .02 & .96 & 11 & .02 & .02 & .95 \\
\hline & 16 & 11 & .02 & .02 & .97 & 8 & .01 & .01 & .96 \\
\hline \multirow{13}{*}{$\begin{array}{l}\text { Abnormal } \\
\text { scores }\end{array}$} & 17 & 2 & .00 & .00 & .98 & 6 & .01 & .01 & .97 \\
\hline & 18 & 1 & .00 & .00 & .98 & 4 & .01 & .01 & .97 \\
\hline & 19 & 5 & .01 & .01 & .99 & 7 & .01 & .01 & .98 \\
\hline & 20 & 2 & .00 & .00 & .99 & 2 & .00 & .00 & .99 \\
\hline & 21 & 4 & .01 & .01 & 1.00 & 1 & .00 & .00 & .99 \\
\hline & 22 & 1 & .00 & .00 & 1.00 & 2 & .00 & .00 & .99 \\
\hline & 23 & 0 & .00 & .00 & 1.00 & 1 & .00 & .00 & .99 \\
\hline & 24 & 0 & .00 & .00 & 1.00 & 1 & .00 & .00 & 1.00 \\
\hline & 25 & 1 & .00 & .00 & 1.00 & 1 & .00 & .00 & 1.00 \\
\hline & 26 & 1 & .00 & .00 & 1.00 & 2 & .00 & .00 & 1.00 \\
\hline & Valid & 655 & .94 & & & 648 & .93 & & \\
\hline & Missing & 40 & .06 & & & 47 & .07 & & \\
\hline & Total & 695 & & & & 695 & & & \\
\hline
\end{tabular}

Note: ${ }^{\text {a }}$ as in Stein et al. (2012); $f=$ observed frequency; $P=$ proportion on total cases; Valid $P=$ proportion on valid cases; Cumulative $P=$ Cumulative proportion 
3. Confirmatory Factor Analysis models for the Strengths and Difficulties Questionnaire

\begin{tabular}{l} 
Model 1 \\
One behavioral problem factor \\
$\rightarrow$ 5. tantrum \\
$\rightarrow$ 12. obeys \\
$\rightarrow$ 18. lies \\
$\rightarrow$ 22. steals \\
$\rightarrow$ 2. restless \\
$\rightarrow$ 10. fidgety \\
$\rightarrow$ 15. distrac \\
$\rightarrow$ 21. reflect \\
$\rightarrow$ 25. attends \\
$\rightarrow$ 3. somatic \\
$\rightarrow$ 13. worries \\
$\rightarrow$ 16. clingy \\
$\rightarrow$ 24. afraid \\
$\rightarrow$ 6. loner \\
$\rightarrow$ 11. friend \\
$\rightarrow$ 14. popular \\
$\rightarrow$ 19. bullied \\
$\rightarrow$ 23. oldbest \\
$\rightarrow$ 1. consid \\
$\rightarrow$ 4. shares \\
$\rightarrow$ 9. caring \\
$\rightarrow$ 17. kind \\
$\rightarrow$ 20. helps \\
\hline
\end{tabular}

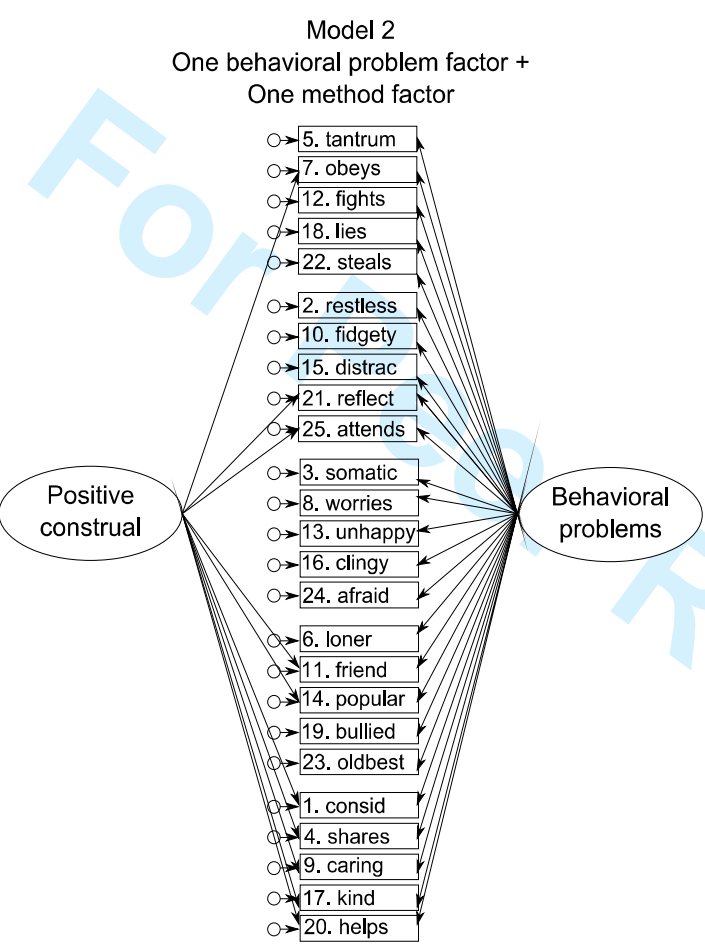

Model 3

Two independent factors

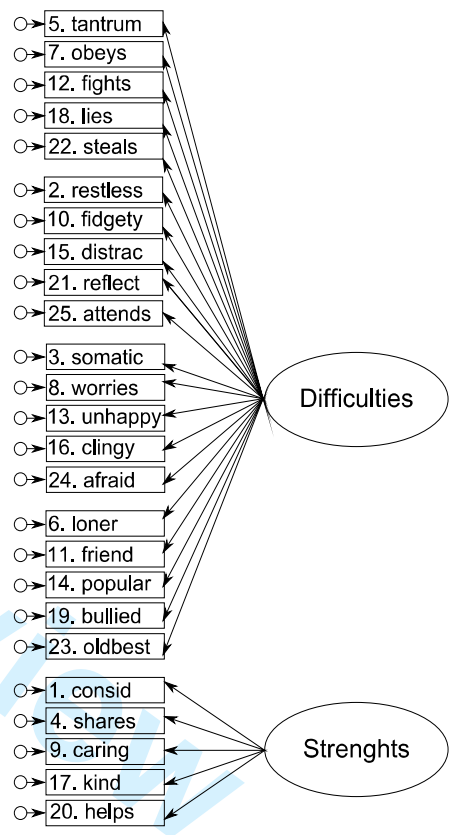

http://mc.manuscriptcentral.com/asmnt 


\section{Confirmatory Factor Analysis models for the Strengths and Difficulties Questionnaire (ctd.)}
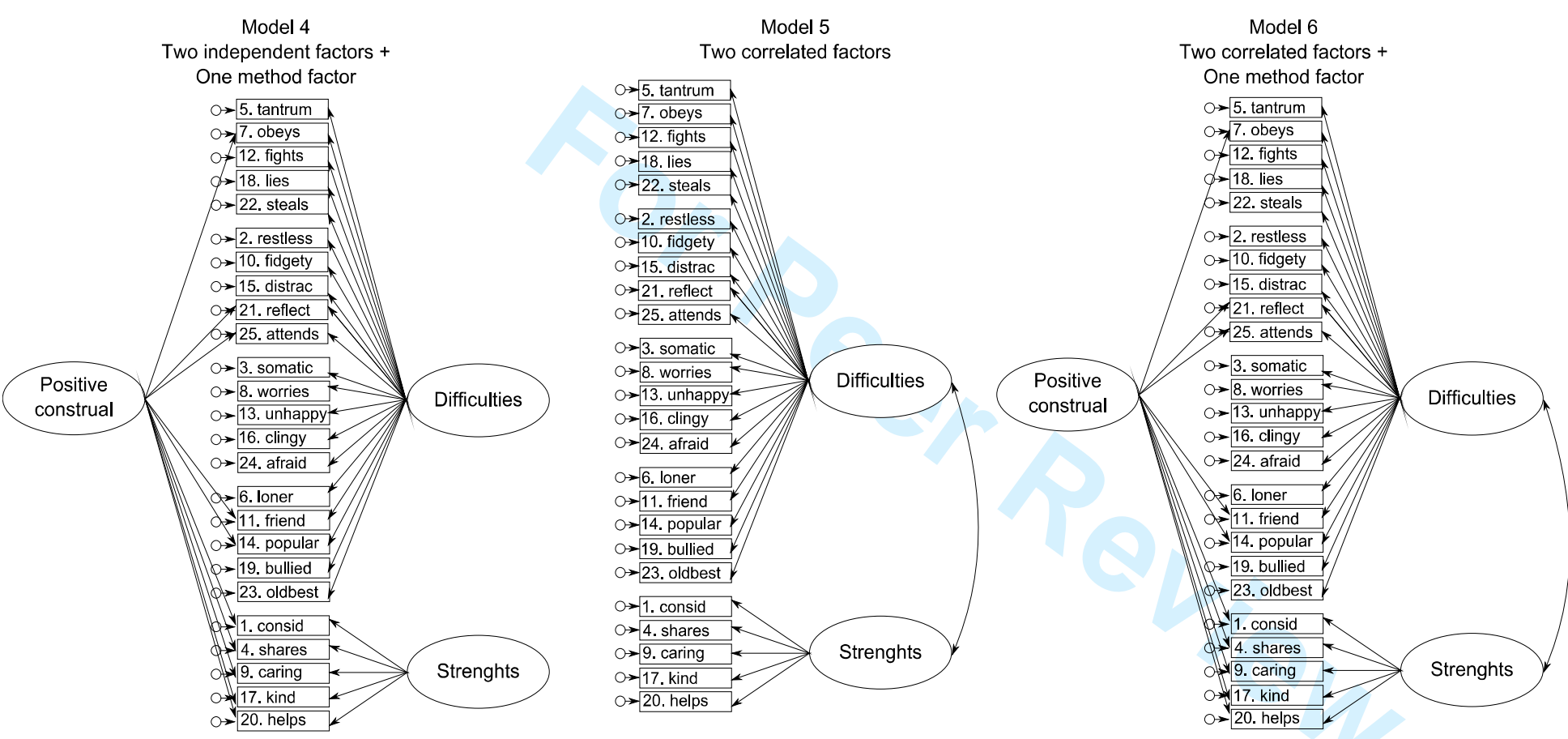

http://mc.manuscriptcentral.com/asmnt 


\section{Confirmatory Factor Analysis models for the Strengths and Difficulties Questionnaire (ctd.)}
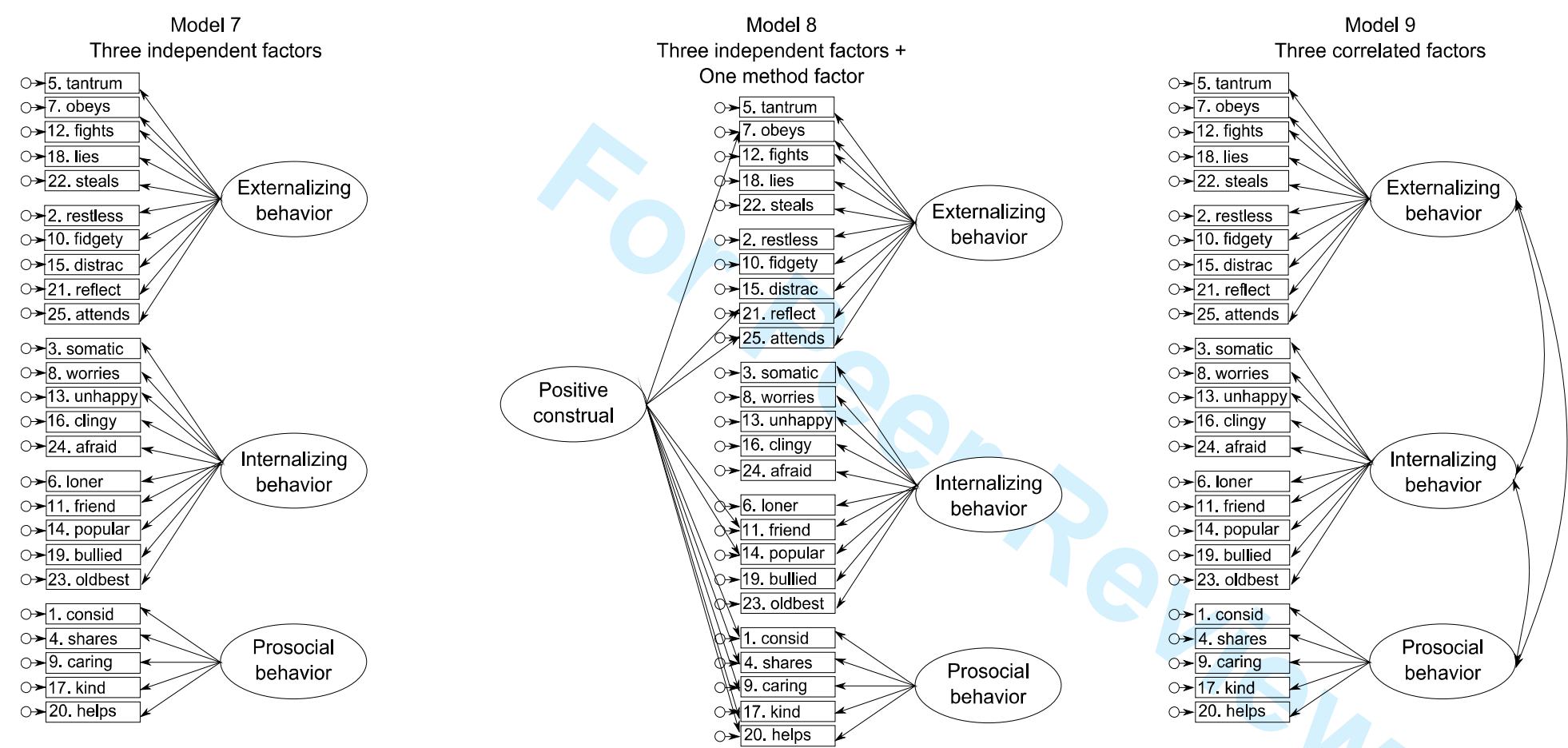

http://mc.manuscriptcentral.com/asmnt 
3. Confirmatory Factor Analysis models for the Strengths and Difficulties Questionnaire (ctd.)
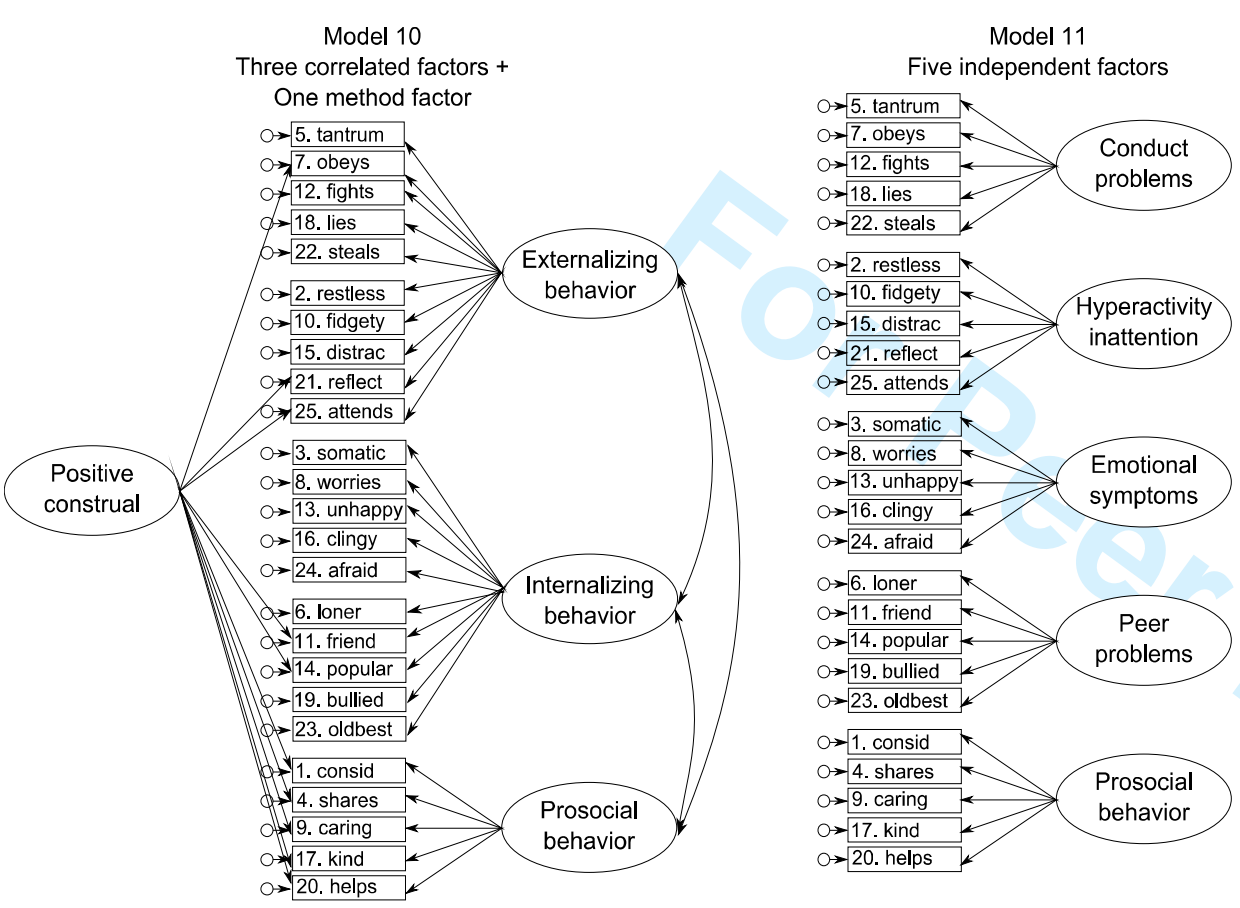

Model 12

Five independent factors +

One method factor

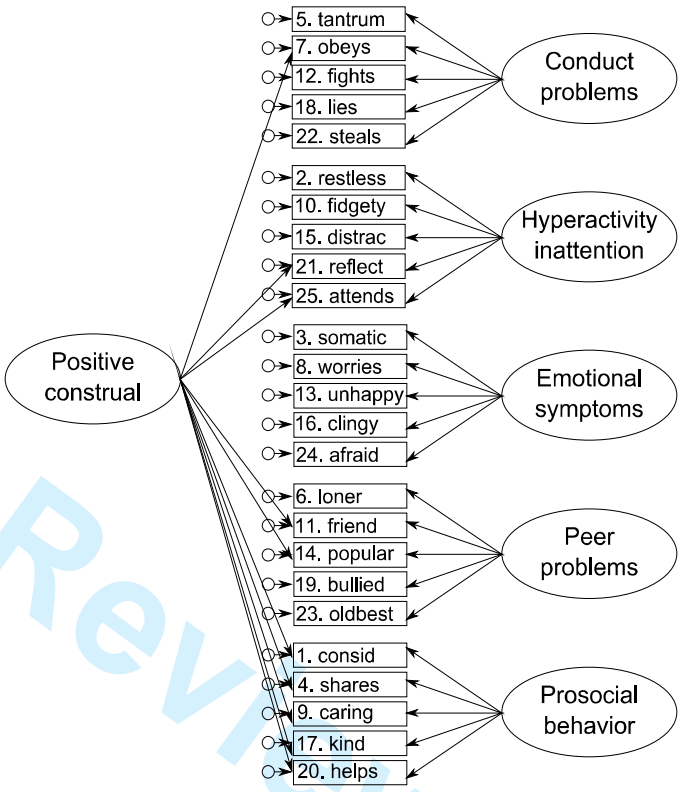

http://mc.manuscriptcentral.com/asmnt 
3. Confirmatory Factor Analysis models for the Strengths and Difficulties Questionnaire (ctd.)

Model 13

Five correlated factors

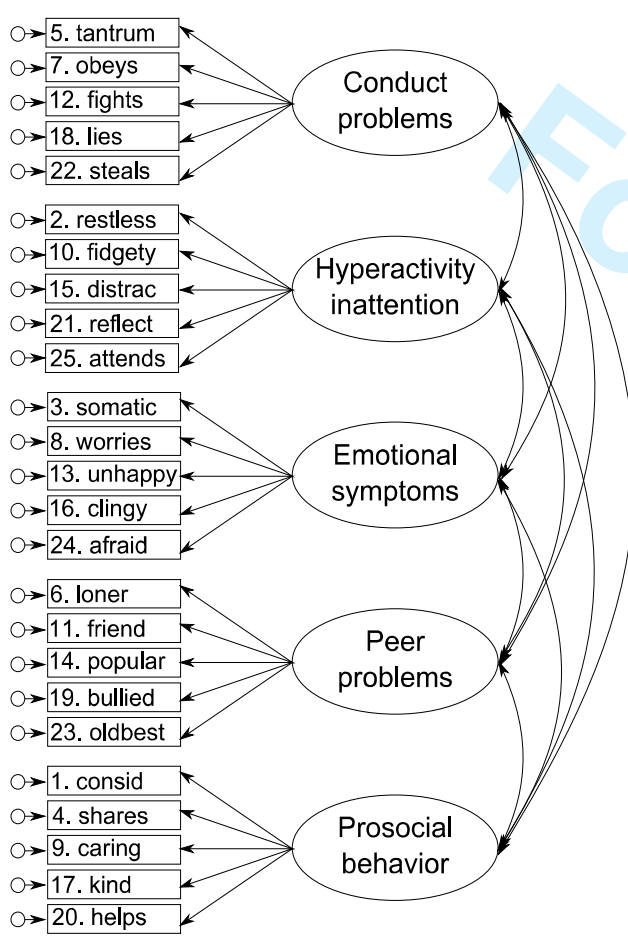

Model 14

Five correlated factors +

One method factor

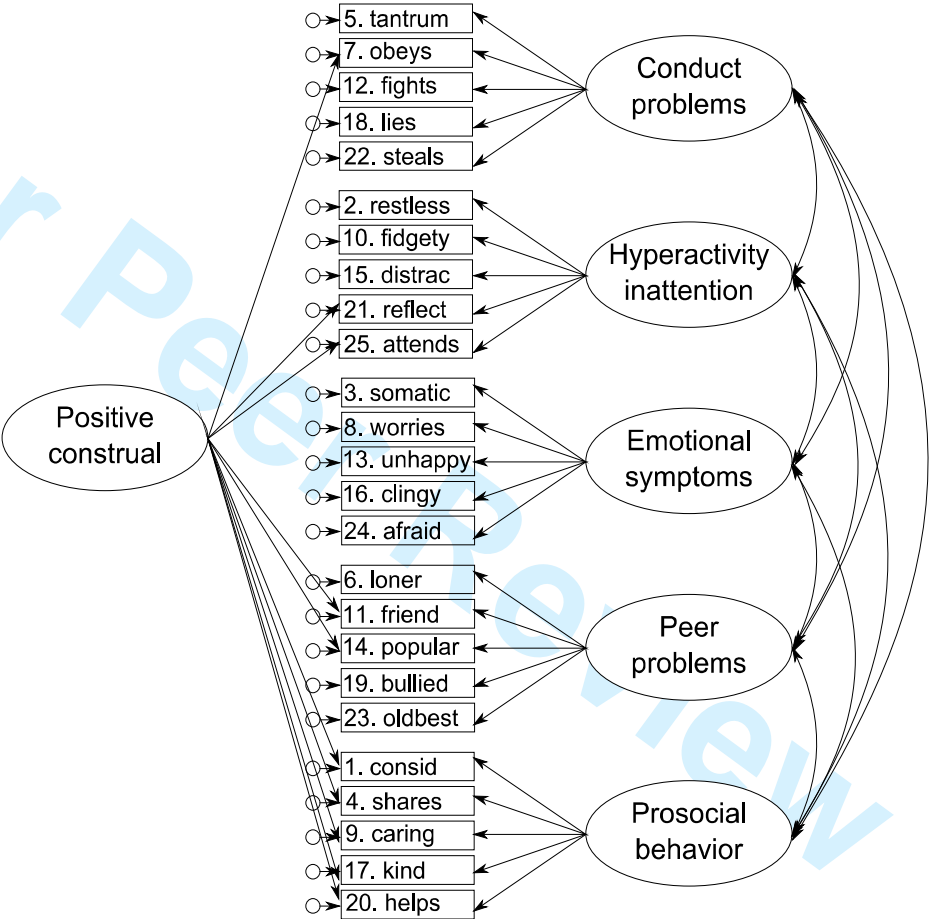




\section{Confirmatory Factor Analysis models for the Strengths and Difficulties Questionnaire (ctd.)}

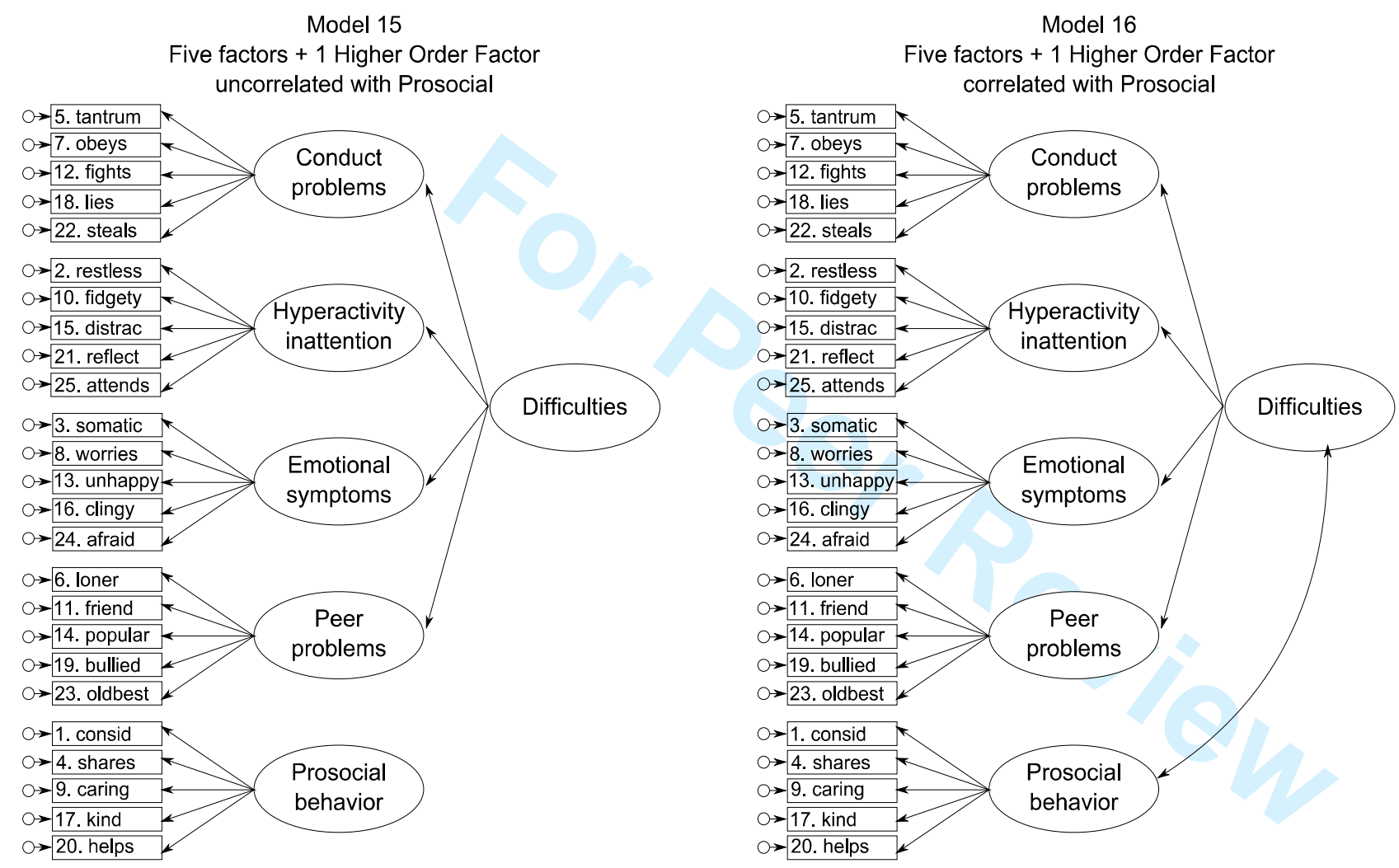

http://mc.manuscriptcentral.com/asmnt 
4. Table 5 Results of Exploratory Structural Equation Models for fathers and mothers separately $(n=695)$ standardized loadings of the pattern matrix (Geomin rotation).

\begin{tabular}{|c|c|c|c|c|c|c|c|c|c|c|c|c|c|c|c|c|c|}
\hline \multirow[b]{2}{*}{ Item } & \multirow[b]{2}{*}{$\begin{array}{l}\text { Expected } \\
\text { factor }\end{array}$} & \multicolumn{7}{|c|}{ Fathers } & \multirow[b]{2}{*}{ RV } & \multicolumn{8}{|c|}{ Mothers } \\
\hline & & 1 & 2 & 3 & 4 & 5 & $\tau_{1}$ & $\tau_{2}$ & & 1 & 2 & 3 & 4 & 5 & $\tau_{1}$ & $\tau_{2}$ & $\mathrm{RV}$ \\
\hline 5. tantrum & COND & .85 & .47 & -.02 & -.18 & -.06 & -0.19 & 1.64 & .48 & .41 & .55 & -.02 & -.36 & -.31 & 0.03 & 1.78 & .53 \\
\hline 7. obeys & COND & .62 & .12 & .05 & -.18 & -.48 & -0.46 & 2.15 & .56 & .29 & .09 & .14 & -.19 & -.71 & -0.50 & 2.28 & .55 \\
\hline 12. fights & COND & .83 & .09 & -.05 & .03 & -.13 & 1.66 & 3.17 & .57 & .71 & .11 & .04 & .01 & -.26 & 1.74 & 3.63 & .58 \\
\hline 18. lies & COND & .52 & .27 & .17 & -.05 & -.10 & 1.02 & 2.86 & .66 & .23 & .43 & .14 & -.30 & -.24 & 1.15 & 3.13 & .65 \\
\hline 22. steals & COND & .38 & .20 & -.01 & -.17 & -.26 & 2.05 & 3.18 & .76 & .17 & .34 & -.09 & -.13 & -.23 & 1.93 & 3.10 & .79 \\
\hline 3. somatic & EMO & .15 & .47 & .03 & -.07 & .23 & 1.25 & 2.43 & .78 & .03 & .65 & .01 & -.05 & .02 & 1.28 & 2.65 & .70 \\
\hline 8. worries & EMO & .06 & .79 & -.09 & .35 & .14 & 1.69 & 3.01 & .53 & -.10 & 1.01 & -.08 & .12 & .04 & 1.67 & 3.58 & .50 \\
\hline 13. unhappy & EMO & .46 & .59 & .05 & .27 & .05 & 1.82 & 2.99 & .52 & .07 & 1.19 & -.02 & -.01 & -.01 & 2.21 & 3.38 & .40 \\
\hline 16. clingy & EMO & -.32 & 1.07 & .00 & .02 & -.07 & -0.14 & 1.86 & .48 & -.51 & 1.04 & .08 & .02 & .02 & 0.03 & 1.95 & .52 \\
\hline 24. afraid & EMO & .02 & .75 & .03 & .13 & .00 & 0.64 & 2.29 & .60 & -.19 & .93 & -.02 & .10 & .03 & 0.85 & 2.39 & .56 \\
\hline 2. restles & HYP & .85 & -.11 & 1.01 & .06 & .01 & -0.33 & 1.73 & .33 & 1.33 & .00 & 1.13 & .02 & -.02 & 0.05 & 2.87 & .22 \\
\hline 10. fidgety & HYP & .73 & .01 & .82 & .07 & .10 & 0.59 & 2.22 & .40 & 1.12 & -.02 & .94 & .02 & .12 & 0.78 & 2.89 & .30 \\
\hline 15. distrac & HYP & .20 & .14 & 1.41 & .04 & .00 & -0.28 & 2.28 & .30 & .24 & .15 & 1.40 & .01 & .00 & -0.12 & 2.59 & .31 \\
\hline 21. reflect & HYP & .13 & -.19 & .64 & -.10 & -.52 & -1.04 & 1.41 & .57 & -.02 & -.01 & .48 & -.16 & -.42 & -1.26 & 1.51 & .65 \\
\hline 25. attends & HYP & -.05 & .01 & 1.22 & -.27 & -.56 & -0.93 & 1.99 & .35 & -.03 & -.02 & 1.85 & -.03 & -.48 & -0.91 & 2.85 & .20 \\
\hline 6. loner & PEER & -.13 & .33 & .11 & .57 & -.19 & 0.64 & 2.40 & .63 & .03 & .33 & .05 & .57 & -.03 & 0.66 & 2.05 & .65 \\
\hline 11. friend & PEER & .08 & -.02 & -.05 & .45 & -.47 & 1.21 & 2.25 & .70 & .00 & .02 & .01 & .71 & -.52 & 1.43 & 2.80 & .57 \\
\hline 14. popular & PEER & -.03 & .11 & -.11 & .49 & -.71 & 1.29 & 3.25 & .57 & .05 & .16 & .14 & .52 & -.52 & 1.23 & 3.86 & .60 \\
\hline 19. bullied & PEER & .15 & .06 & .03 & .44 & .24 & 1.61 & 2.66 & .76 & .15 & .32 & -.03 & .41 & -.06 & 1.62 & 2.62 & .72 \\
\hline 23. oldbest & PEER & .00 & .03 & .06 & 1.88 & -.02 & 1.38 & 3.92 & .22 & .41 & .16 & -.02 & .67 & .01 & 0.80 & 2.23 & .58 \\
\hline 1. consid & PRO & -.45 & -.01 & -.09 & -.01 & .87 & -2.90 & 0.16 & .47 & -.14 & .01 & .05 & .02 & 1.09 & -3.56 & -0.25 & .45 \\
\hline 4. shares & PRO & -.16 & -.12 & -.04 & -.10 & .58 & -1.93 & 0.35 & .68 & -.04 & -.07 & -.09 & -.04 & .56 & -2.15 & 0.34 & .73 \\
\hline 9. caring & PRO & .00 & .04 & .05 & -.11 & .82 & -2.93 & -0.70 & .60 & .10 & .13 & .09 & -.29 & 1.08 & -3.05 & -0.75 & .46 \\
\hline 17. kind & PRO & -.33 & .07 & .23 & -.32 & .86 & -3.37 & -0.76 & .50 & .01 & .12 & .00 & -.32 & 1.05 & -3.83 & -0.90 & .47 \\
\hline \multirow[t]{5}{*}{ 20. helpout } & PRO & .20 & -.07 & -.15 & .01 & .91 & -2.22 & 0.11 & .54 & .37 & -.05 & -.13 & -.04 & .70 & -2.31 & -0.03 & .63 \\
\hline & $r$ with 2 & .26 & & & & & & & & .40 & & & & & & & \\
\hline & $r$ with 3 & .23 & .19 & & & & & & & .18 & .16 & & & & & & \\
\hline & $r$ with 4 & .18 & .30 & .16 & & & & & & -.02 & .21 & -.08 & & & & & \\
\hline & $r$ with 5 & -.16 & -.15 & -.06 & .00 & & & & & -.16 & -.16 & -.24 & .03 & & & & \\
\hline
\end{tabular}

Note: Bolded coefficients are higher than $|.30|$. Italicized coefficients are significant at $\mathrm{p}<.01 . \tau_{1}$ and $\tau_{2}$ : item thresholds; $\mathrm{RV}=$ items residual variance; 
Note that factor loadings are pattern coefficients, i.e., weights applied to the indicators to obtain scores on the latent variables, analogous to the beta weights in multiple regression. This means that these loadings do not need to be less than $|1.00|$, as in the case of uncorrelated factors, in which they are actually correlation coefficients (see, e.g. Thompson, 2004, p. 16). Loadings in the pattern matrix can be larger than 11, unlike the loadings in the structure matrix, which cannot (Thompson, 2004).

$\mathrm{COND}=$ conduct problems; $\mathrm{EMO}=$ emotional symptoms; $\mathrm{HYP}=$ hyperactivity-inattention; $\mathrm{PEER}=$ peer problems; $\mathrm{PRO}=$ prosocial behavior 


\section{References for this Supporting Information}

Becker, A., Woerner, W., Hasselhorn, M., Banaschewski, T., \& Rothenberger, A. (2004). Validation of the parent and teacher SDQ in a clinical sample. European Child \& Adolescent Psychiatry, 13 [Suppl 2], II/11-II/16. doi: 10.1007/s00787-004-2003-5.

Capron, C., Therond, C., \& Duyme, M. (2007). Psychometric properties of the French version of the self-report and teacher Strengths and Difficulties Questionnaire (SDQ). European Journal of Psychological Assessment, 23, 79-88. doi: 10.1027/1015-5759.23.2.79.

d'Acremont, M., \& Van der Linden, M. (2008). Confirmatory factor analysis of the Strengths and Difficulties Questionnaire in a community sample of French-speaking adolescents. European Journal of Psychological Assessment., 24, 1-8. doi: 10.1027/1015-5759.24.1.1.

Di Riso, D., Salcuni, S., Chessa, D., Raudina, A., Lis, A., \& Altoé, G. (2010). The Strengths and Difficulties Questionnaire (SDQ). Early evidence of its reliability and validity in a community sample of Italian children. Personality and Individual Differences, 49, 570-575. doi: 10.1016/j.paid.2010.05.005.

Dickey, W., C., \& Blumberg, S., J. (2004). Revisiting the factor structure of the Strengths and Difficulties Questionnaire: United States, 2001. Journal of the American Academy of Child \& Adolescent Psychiatry, 43, 1159-1167. doi: 10.1097/01.chi.0000132808.36708.a9.

Du, Y., Kou, J., \& Coghill, D. (2008). The validity, reliability and normative scored of the parent, teacher and self report versions of the Strengths and Difficulties Questionnaire in China. Child and Adolescent Psychiatry and Mental Health, 2, 8. doi:10.1186/1753-2000-2-8.

Essau, C. A., Olaya, B., Anastassiou-Hadjicharalambous, X., Pauli, G., Gilvarry, C., Bray, D., O'Callaghan, J., \& Ollendick, T. H. (2012). Psychometric properties of the Strength and Difficulties Questionnaire from five European countries. International Journal of Methods in Psychiatric Research, 21, 232-245. doi: 10.1002/mpr.1364.

Ezpeleta, L., Granero, R., de la Osa, N., Penelo, E., \& Domenèch, J. M. (2013). Psychometric properties of the Strengths and Difficulties Questionnaire 3-4 in 3-year-old preschoolers. Comprehensive Psychiatry, 54, 282-291. doi: 10.1016/j.comppsych.2012.07.009.

Giannakopoulous, G., Tzavara, C., Dimitrakaki, C., Kolaitis, G., Rotsika, V., \& Tountas, Y. (2009). The Factor Structure of the Strengths and Difficulties Questionnaire (SDQ) in Greek adolescents. Annals of General Psychiatry, 8, 20. doi:10.1186/1744-859X-8-2.

Gomez-Beneyto, M., Nolasco, A., Moncho, J., Pereyra-Zamora, P., Tamayo-Fonseca, N., Munarriz, M., Salazar, J., Tabarés-Seisdedos, R., \& Girón, M. (2013). Psychometric behaviour of the Strengths and Difficulties Questionnaire (SDQ) in the Spanish National Health Survey 2006. BMC Psychiatry, 13, 95. doi: 10.1186/1471-244X-13-95.

Goodman, A., Lamping, D. L., \& Ploubidis, G. B. (2010). When to use broader internalising and externalising subscales instead of the hypothesised five subscales on the Strengths and Difficulties Questionnaire (SDQ): Data from British parents, teachers and children. Journal of Abnormal Child Psychology, 38, 1179-1191. doi: 10.1007/s10802-010-9434-x.

Goodman, R. (2001). Psychometric properties of the Strengths and Difficulties Questionnaire, Journal of the American Academy of Child \& Adolescent Psychiatry, 40, 1337-1345. doi: 10.1097/00004583-200111000-00015.

Hagquist, C. (2007). The psychometric properties of the self-reported SDQ - An analysis of Swedish data based on the Rasch model. Personality and Individual Differences, 43, 12891301. doi: 10.1016/j.paid.2007.03.022

Hawes, D., J., \& Dadds, M. R. (2004). Australian data and psychometric properties of the Strengths and Difficulties Questionnaire. Australian \& New Zealand Journal of Psychiatry, 38, 644-651. doi: 10.1111/j.1440-1614.2004.01427.x.

Haynes, A., Gilmore, L., Shochet, I., Campbell, M., \& Roberts, C. (2013). Factor analysis of the self-report version of the strengths and difficulties questionnaire in a sample of children with 
intellectual disability. Research In Developmental Disabilities, 34, 847-854. doi: 10.1016/j.ridd.2012.11.008.

He, J-P., Burstein, M., Schmitz, A., \& Merikangas, K. R. (2013). The Strengths and Difficulties Questionnaire (SDQ): The factor structure and scale validation in U.S. adolescents. Journal of Abnormal Child Psychology, 41, 583-595. doi: 10.1007/s10802-012-9696-6.

Hill, C., R., \& Hughes, J. N. (2007). An examination of the convergent and discriminant validity of the Strengths and Difficulties Questionnaire. School Psychology Quarterly, 22, 380-406. doi: 10.1037/1045-3830.22.3.380.

Kashala, E., Elgen, I., Sommerfelt, K. \& Tylleskar, T. (2005). Teacher ratings of mental health among school children in Kinshasa, Democratic Republic of Congo. European Child \& Adolescent Psychiatry. 14, 208-215. doi: 10.1007/s00787-005-0446-y.

Koskelainen, M., Sourander, A., \& Kaljonen, A. (2000). The Strengths and Difficulties Questionnaire among Finnish school-aged children and adolescents. European Child \& Adolescent Psychiatry, 9, 277-284. doi: 10.1007/s007870070031.

Mansbach-Kleinfeld, I., Apter, A., Farbstein, I., Levine, S. Z., \& Ponizovsky, A. M. (2010). A population-based psychometric validation study of the Strengths and Difficulties Questionnaire - Hebrew version. Frontiers in Psychiatry, 1, 151. doi: 10.3389/fpsyt.2010.00151.

Matsuishi, T., Nagano, M., Araki, Y., Tanaka, Y., Iwasaka, M., Yamashita, Y., Nagamitsu, S., Lizuka, C., Ohya, T., Shibuya, K., Hara, M., Matsuda, K., Tsuda, A., \& Kakuma, T. (2008). Scale properties of the Japanese version of the Strengths and Difficulties Questionnaire (SDQ): A study of infant and school children in community samples. Brain \& Development, 30, 410415. doi: 10.1016/j.braindev.2007.12.003.

McCrory, C., \& Layte, R. (2012). Testing competing models of the Strengths and Difficulties Questionnaire's (SDQ's) factor structure for the parent-informant instrument. Personality and Individual Differences, 52, 882-887. doi: 10.1016/j.paid.2012.02.011.

McDonald, R. P. (1985). Factor analysis and related methods. Hillsdale NJ: Erlbaum.

Mellor, D., \& Stokes, M.(2007). The factor structure of the Strengths and Difficulties Questionnaire. European Journal of Psychological Assessment., 23, 105-112. doi: 10.1027/1015-5759.23.2.105

Muris, P., Meesters, C., \& van den Berg, F. (2003). The Strengths and Difficulties Questionnaire (SDQ): Further evidence for its reliability and validity in a community sample of Dutch children and adolescents. European Child \& Adolescent Psychiatry, 12, 1-8. doi: 10.1007/s00787-003-0298-2.

Muris, P., Meesters, C., Eijkelenboom, A., \& Vincken, M. (2004). The self-report version of the Strengths and Difficulties Questionnaire: Its psychometric properties in 8- to 13-year old nonclinical children. British Journal of Clinical Psychology, 43, 437-448. doi: $10.1348 / 0144665042388982$.

Niclasen, J., Skovgaard, A. M., Nybo Andersen, A.-M., Sømhovd, M. J., \& Obel, C. (2012). A confirmatory approach to examining the factor structure of the Strengths and Difficulties Questionnaire (SDQ): A large scale cohort study. Journal of Abnormal Child Psychology, 41, 355-365. doi: 10.1007/s10802-012-9683-y.

Niclasen, J., Teasdale, T. W., Nybo Andersen, A.-M., Skovgaard, A. M., Elberling, H., \& Obel, C. (2012). Psychometric properties of the Danish Strength and Difficulties Questionnaire: The SDQ assessed for more than 70,000 raters in four different cohorts. PLOS One, e32025. doi: 10.1371/journal.pone.0032025.

Palmieri, P. A., \& Smith, G. C. (2007). Examining the structural validity of the Strengths and Difficulties Questionnaire (SDQ) in a U.S. Sample of custodial grandmothers. Psychological Assessment, 19, 189-198. doi: 10.1037/1040-3590.19.2.189.

Percy, A., McCrystal, P., \& Higgins, K. (2008). Confirmatory factor analysis of the adolescent selfreport Strengths and Difficulties Questionnaire. European Journal of Psychological Assessment., 24, 43-48. doi: 10.1027/1015-5759.24.1.43. 
Raykov, T. (1997). Scale reliability, Cronbach's coefficient alpha, and violations of essential tauequivalence with fixed congeneric components. Multivariate Behavioral Research, 32, 329353. doi:10.1207/s15327906mbr3204_2.

Richter, J., Sagatun, A., Heyerdahl, S., Oppedal, B., \& Roysamb, E. (2011). The Strengths and Difficulties Questionnaire (SDQ) - Self-Report. An analysis of its structure in a multiethnic urban adolescent sample. Journal of Child Psychology and Psychiatry, 52, 1002-1011. doi: 10.1111/j.1469-7610.2011.02372.x.

Rønning, J. A., Helge Handegaard, B., Sourander, A., \& Mørch, W.-T. (2004). The Strengths and Difficulties Self-Report Questionnaire as a screening instrument in Norwegian community samples. European Child \& Adolescent Psychiatry, 13, 73-82. doi: 10.1007/s00787-004-03564.

Rothenberger, A., Becker, A., Erhart, M., Wille, N., Ravens-Sieberer, U., \& the BELLA Study Group (2008). Psychometric properties of the parent strengths and difficulties questionnaire in the general population of German children and adolescents: results of the BELLA study. European Child \& Adolescent Psychiatry, 17 [Suppl 1], 99-105. doi: 10.1007/s00787-008$1011-2$.

Ruchkin, V., Jones, S., Vermeiren, R., \& Schwab-Stone, M. (2008). The Strengths and Difficulties Questionnaire: The self-report version in American urban and suburban youth. Psychological Assessment, 20, 175-182. doi: 10.1037/1040-3590.20.2.175.

Sanne, B., Torsheim, T., Heiervang, E., \& Stormark, K. M. (2009). The Strengths and Difficulties Questionnaire in the Bergen Child Study: A conceptually and methodically motivated structural analysis. Psychological Assessment, 21,352-364. doi: 10.1037/a0016317.

Shevlin, M., Murphy, S., McElearney, A., O'Kane, D., Tracey, A., \& Adamson, G. (2012). Confirmatory factor analysis of adolescent self- and informant ratings of the Strengths and Difficulties Questionnaire. Irish Journal of Psychology, 3, 17-28. doi: 10.1080/03033910.2011.649569.

Smedje, H., Broman, J-E., Hetta, J., \& von Knorring, A-L. (1999). Psychometric properties of a Swedish version of the Strengths and Difficulties Questionnaire. European Child \& Adolescent Psychiatry, 8, 63-70. doi: 10.1007/s007870050086.

Stein, A., Malmberg, L-E., Sylva, K., Leach, P., Barnes, J., \& the FCCC group (2012). The influence of different forms of early childcare on children's emotional and behavioural development at school entry. Child: Care, Health and Development, 39, 676-687. doi: 10.1111/j.1365-2214.2012.01421.x.

Stone, L. L., Otten, R., Engels, R. C., Vermulst, Ad A., \& Janssens, J. M. A. M. (2010). Psychometric properties of the parent and teacher versions of the Strengths and Difficulties Questionnaire for 4- to 12-year-olds: A review. Clinical Child and Family Psychology Review, 13, 254-274. doi: 10.1007/s10567-010-0071-2.

Stone, L. L., Ottne, R., Ringlever, L., Hiemstra, M., Engels, R. C. M. E., Vermulst, Ad A., \& Janssens, J. M. A. M. (2013). The Parent version of the Strengths and Difficulties Questionnaire: Omega as an alternative to alpha and a test for measurement invariance. European Journal of Psychological Assessment., 29, 44-50. doi: 10.1027/1015-5759/a000119.

Thompson, B. (2004). Exploratory and Confirmatory Factor Analysis. Understanding Concepts and Applications. Washington, DC: American Psychological Association.

Van de Looij-Jansen, P. M., Goedhart, A. W., de Wilde, E. J., \& Treffers, P. D. A. (2011). Confirmatory factor analysis and factorial invariance analysis of the adolescent self-report Strengths and Difficulties Questionnaire: How important are method effects and minor factors? British Journal of Clinical Psychology, 50, 127-144. doi: 10.1348/014466510X498174.

Van Leeuwen, K., Meerschaert, T., Bosmans, G., De Medts, L., \& Braet, C. (2006).The Strengths and Difficulties Questionnaire in a community sample of young children in Flanders. European Journal of Psychological Assessment., 22, 189-197. doi: 10.1027/1015-5759.22.3.189. 
Van Roy, B., Veenstra, M., \& Clench-Aas, J. (2008). Construct validity of the five-factor Strengths and Difficulties Questionnaire (SDQ) in pre-, early, and late adolescence. Journal of Child Psychology and Psychiatry, 49, 1304-1312. doi: 10.1111/j.1469-7610.2008.01942.x.

Woerner, W., Becker, A., \& Rothenberger, A. (2004). Normative data and scale properties of the German parent SDQ. European Child \& Adolescent Psychiatry, 13, 3-10. doi: 10.1007/s00787004-2002-6.

Yao, S., Zhang, C., Zhu, X., Jing, X., McWhinnie, C. M., \& Abela, J. R. Z. (2009). Measuring adolescent psychopathology: Psychometric properties of the Self-Report Strengths and Difficulties Questionnaire in a sample of Chinese adolescents. Journal of Adolescent Health, 45, 55-62. doi: 10.1016/j.jadohealth.2008.11.006. 